Article

\title{
Impact of Mineral Reactive Surface Area on Forecasting Geological Carbon Sequestration in a $\mathrm{CO}_{2}$-EOR Field
}

\author{
Wei Jia ${ }^{1,2} \mathbb{D}$, Ting Xiao ${ }^{1,2}\left(\mathbb{D}\right.$, Zhidi $\mathrm{Wu}^{1,2}$, Zhenxue Dai ${ }^{3} \mathbb{D}$ and Brian McPherson ${ }^{1,2, *}$ \\ 1 Energy \& Geoscience Institute, University of Utah, Salt Lake City, UT 84108, USA; wei.jia@utah.edu (W.J.); \\ ting.xiao@utah.edu (T.X.); zhidi.wu@utah.edu (Z.W.) \\ 2 Department of Civil \& Environmental Engineering, University of Utah, Salt Lake City, UT 84112, USA \\ 3 College of Construction Engineering, Jilin University, Changchun 130026, China; dzx@jlu.edu.cn \\ * Correspondence: b.j.mcpherson@utah.edu
}

check for

updates

Citation: Jia, W.; Xiao, T.; Wu, Z.; Dai, Z.; McPherson, B. Impact of Mineral Reactive Surface Area on Forecasting Geological Carbon Sequestration in a $\mathrm{CO}_{2}$-EOR Field. Energies 2021, 14 , 1608. https://doi.org/10.3390/ en14061608

Academic Editors:

Nikolaos Koukouzas and João Fernando Pereira Gomes

Received: 1 February 2021

Accepted: 11 March 2021

Published: 14 March 2021

Publisher's Note: MDPI stays neutral with regard to jurisdictional claims in published maps and institutional affiliations.

Copyright: (c) 2021 by the authors. Licensee MDPI, Basel, Switzerland. This article is an open access article distributed under the terms and conditions of the Creative Commons Attribution (CC BY) license (https:// creativecommons.org/licenses/by/ $4.0 /)$.

\begin{abstract}
Mineral reactive surface area (RSA) is one of the key factors that control mineral reactions, as it describes how much mineral is accessible and can participate in reactions. This work aims to evaluate the impact of mineral RSA on numerical simulations for $\mathrm{CO}_{2}$ storage at depleted oil fields. The Farnsworth Unit (FWU) in northern Texas was chosen as a case study. A simplified model was used to screen representative cases from 87 RSA combinations to reduce the computational cost. Three selected cases with low, mid, and high RSA values were used for the FWU model. Results suggest that the impact of RSA values on $\mathrm{CO}_{2}$ mineral trapping is more complex than it is on individual reactions. While the low RSA case predicted negligible porosity change and an insignificant amount of $\mathrm{CO}_{2}$ mineral trapping for the FWU model, the mid and high RSA cases forecasted up to $1.19 \%$ and $5.04 \%$ of porosity reduction due to mineral reactions, and $2.46 \%$ and $9.44 \%$ of total $\mathrm{CO}_{2}$ trapped in minerals by the end of the 600-year simulation, respectively. The presence of hydrocarbons affects geochemical reactions and can lead to net $\mathrm{CO}_{2}$ mineral trapping, whereas mineral dissolution is forecasted when hydrocarbons are removed from the system.
\end{abstract}

Keywords: geological carbon sequestration; reactive surface area; mineral trapping; enhanced oil recovery with $\mathrm{CO}_{2}\left(\mathrm{CO}_{2}\right.$-EOR); geochemical reactions; risk assessment

\section{Introduction}

Geological carbon sequestration (GCS) is a critical component in accomplishing the goal of net-zero or carbon neutrality set by governments and industries [1-3], as it provides an enormous estimated storage capacity, and its efficacy has been successfully demonstrated many times by pilot-scale and field-scale projects worldwide [4]. Among the storage options, GCS at depleted oil fields, especially enhanced oil recovery with $\mathrm{CO}_{2}$ $\left(\mathrm{CO}_{2}\right.$-EOR), has drawn a lot of attention, because of the higher economic incentives (in addition to government subsidies, e.g., the $45 \mathrm{Q}$ tax credit in the U.S.) and the lower costs of characterization, construction, and deployment. While most $\mathrm{CO}_{2}$ trapping mechanism analyses were performed for GCS at deep saline aquifers (e.g., [5]), the essence of the trapping mechanisms is similar for $\mathrm{CO}_{2}$-EOR projects [6-8]. However, one particular trapping mechanism, the mineral trapping of $\mathrm{CO}_{2}$, is often ignored in storage forecasts for $\mathrm{CO}_{2}$-EOR projects, such as Jia et al., 2016 [6], even though mineral trapping is the most secure mechanism to sequester $\mathrm{CO}_{2}$ in the long term. Due to the lack of geochemical modeling in these forecasts, the processes of $\mathrm{CO}_{2}$ dissolution and its presence in aqueous ions are also ignored. However, understanding the geochemical interactions between $\mathrm{CO}_{2}$, in situ fluid, and formation, is critical to ensure long term $\mathrm{CO}_{2}$ conformance and to mitigate the risks of groundwater contamination due to $\mathrm{CO}_{2}$ leakage.

Mineral reactions are numerically described via two key parameters: chemical equilibrium constant and mineral dissolution and precipitation reaction rate. For a given reaction, 
the chemical equilibrium constant is a function of temperature, whereas the mineral reaction rate is controlled by further factors. As defined in the Transition State Theory (TST), the mineral reaction rate is a function of reactive surface area (RSA), activation energy, temperature, and equilibrium constant [9]. Particularly, the mineral RSA is crucial as it determines how much mineral is accessible and can participate in the reactions, yet it has been a challenge for it to be fully characterized. There are several approaches to measuring the mineral RSA (or specific surface area) in the laboratory, such as the widely used Brunauer-Emmett-Teller (BET) method [10], and newer image-based methods [11,12]. However, neither of these methods is ideal for characterizing mineral RSA. For example, the geometry-based method is constrained to the assumption of uniform-sized mineral grains, and thus its performance is compromised for the heterogeneously shaped mineral grains; on the other hand, the image-based methods need a drastically large number of images to capture the evolving mineral RSA over time. Therefore, it is common to observe order of magnitude differences in RSA measurements for the same mineral [13]. Such wide ranges of uncertainty pose great challenges in selecting parameters for numerical simulations. Even worse, most GCS simulation tools that include geochemical modules (e.g., CMG-GEM, TOUGHReact) ignore the spatial and geometry heterogeneity of mineral RSA values and simplify the temporal variation of mineral RSA values.

Existing uncertainty studies for GCS primarily focus on uncertainties stemming from porosity, permeability, and operational factors (e.g., injection scheme) [6,14-20]. Only a few studies have examined the impact of uncertain reactive surface areas on GCS performances. Qin and Beckingham (2021) compared simulation results of a core-scale model using mineral RSA obtained from different methods [21]. Luo et al., 2012 investigated the effect of the RSA of calcite and anorthite using a two-dimensional (2D) generic deep saline aquifer model and confirmed that these parameters have a significant impact on $\mathrm{CO}_{2}$ mineral trapping [22]. Bolourinejad et al., 2014 followed a similar approach to evaluate the impact of the RSA of seven minerals on $\mathrm{CO}_{2}$ trapping for a depleted gas field in the Netherlands [23]. It was found that the RSA of quartz has the greatest impact on $\mathrm{CO}_{2}$ mineral trapping; however, neither hydrocarbon components nor realistic field operations were taken into consideration in their numerical model. Moreover, both Luo et al., 2012 and Bolourinejad et al., 2014 employed only one well (the injector) in their simulations. Recently, Jia et al., 2019 studied $\mathrm{CO}_{2}$ trapping mechanisms, including mineral trapping, for an ongoing $\mathrm{CO}_{2}-$ EOR project with multiple five-spot well patterns, but only briefly discussed the potential impacts of using different mineral RSA values in their simulations [22-24].

This work aims to evaluate the impact of mineral reactive surface area on GCS numerical simulations where hydrocarbons are present. The novelty of this work includes: (1) using a three-dimensional (3D) field-scale reservoir model to eliminate the boundary effects imposed by 2D models; (2) using site-specific formation and fluid properties as well as realistic operational activities, i.e., $\mathrm{CO}_{2}$-EOR with multiple wells; and (3) taking hydrocarbon components into consideration, thus simulating reactive transport for the three-phase system (water, gas, and oil). The Farnsworth Unit (FWU) site in northern Texas is selected as a case study. As the study site of the Southwest Regional Partnership on Carbon Sequestration (SWP) Phase III, the FWU site has been investigated with many characterization and monitoring techniques (e.g., [25-28]) and numerical analyses (e.g., $[7,8,14,15,24,29,30])$.

The rest of this paper is structured as follows: Section 2 describes the FWU reservoir model and the methods to evaluate the impact of mineral reactive surface areas; Sections 3 and 4 present simulation results and discuss how the presence of hydrocarbon components and uncertain RSA values affect reactive transport and $\mathrm{CO}_{2}$ mineral trapping; and Section 5 summarizes the findings of this work. 


\section{Materials and Methods}

\subsection{FWU Description}

The FWU site is located in the Anadarko basin in northern Texas (Figure 1a). Following the primary and secondary production that started in the 1950s and 1960s, the FWU has been currently undergoing $\mathrm{CO}_{2}$-EOR since December 2010. As of 2020, more than one million metric tons of $\mathrm{CO}_{2}$ has been sequestered at the FWU [31].

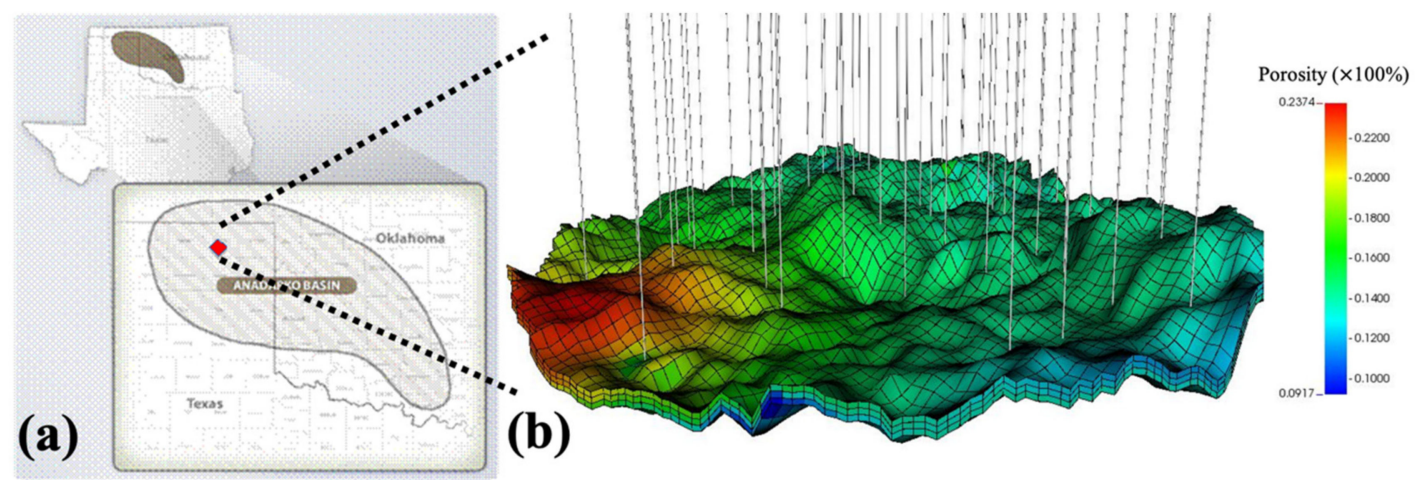

Figure 1. (a) Location of the Farnsworth Unit (FWU), and (b) a three-dimensional (3D) reservoir model of the Farnsworth Unit.

The $\mathrm{CO}_{2}$ storage system at the FWU consists of late Pennsylvanian Morrow B sandstone as the storage formation and overlying Atokan Thirteen Finger limestone as the sealing layer. With the support of the U.S. Department of Energy and the National Energy Technology Laboratory, the SWP team has been conducting a variety of characterization; monitoring, verification, and accounting (MVA); simulation; and risk assessment research activities over the past decade. For the sake of brevity, please refer to previous publications for the details of $\mathrm{CO}_{2}$ sequestration at the FWU. For example, Ross-Coss et al., 2015 and Ampomah et al., 2016 focused on geological characterization performed at the FWU [26,32]; Kumar et al., 2018 and Balch et al., 2017 presented MVA findings at the FWU [28,33]; Ampomah et al., 2016, Moodie et al., 2017, and Moodie et al., 2019 presented numerical simulation results for GCS forecast at the FWU [34-36]; and Dai et al., 2016, Pan et al., 2016, Xiao et al., 2016, Jia et al., 2017, and Xiao et al., 2020 addressed uncertainty analysis due to both geological and operational factors and quantitative risk assessment of $\mathrm{CO}_{2}$ leakage and its impact on overlying underground sources of drinking water [16,17,37-39]. This study is built upon this previous FWU work and focuses on risk assessments associated with reactive transport, in particular mineral reactive surface areas.

\subsection{Mineral Reactive Surface Area}

The reactive surface area of minerals is a dynamic property that varies from mineral to mineral, changes over time as geochemical reactions develop, and depends on the heterogeneous distributions, various shapes, and complex contact interfaces of all minerals in the subsurface. A variety of methods are available to characterize mineral reactive surface areas, such as the well-known BET (Brunauer-Emmett-Teller) approach, analytical methods based on kinetic experiments, and the image-based approaches that rely on scanning electron microscopy (SEM) and computed tomography (CT) techniques $[11,40]$. These methods have been used for measuring mineral reactive surface areas for GCS purposes, e.g., [40,41]. As expected, the measured reactive surface area of the same mineral drastically varies from method to method and from site to site. For example, Bolourinejad et al., 2014 measured the specific surface area of kaolinite in the Rotliegend reservoir cores in the range of $1.2 \times 10^{6} \mathrm{~m}^{2} / \mathrm{m}^{3} \sim 3.4 \times 10^{7} \mathrm{~m}^{2} / \mathrm{m}^{3}$; Beckingham et al., 2016 reported different specific surface areas of calcite, ranging from $8.1 \times 10^{4} \mathrm{~m}^{2} / \mathrm{m}^{3}$, measured by the BET approach, to $7.6 \times 10^{5} \mathrm{~m}^{2} / \mathrm{m}^{3}$, measured by image-based methods [11,23]. The term specific surface area (SSA) is generally used to describe the reactivity of the pure mineral, 
while the term reactive surface area (RSA) is usually referred to as the average reactivity of each mineral in the porous media. Therefore, the SSA values need to be converted to RSA values with site-specific mineral volume fractions. At the FWU, there are seven key minerals identified from core analyses. A survey of the reactive surface area of these minerals was performed and is summarized in Table 1. Please note that mineral volume fractions (listed in Table 2) were used to convert the SSA values reported in other studies to FWU site-specific RSA values. The several orders of magnitude difference between the lower and upper values in Table 1 reiterate the primary research question of this study of whether the choice of a reactive surface area value impacts the results of reactive transport simulation and to what extent.

Table 1. Ranges of reactive surface area (RSA) of seven minerals from a literature survey $[11,22-24,40,41]$.

\begin{tabular}{cccccccc}
\hline RSA $\left(\mathbf{m}^{2} / \mathbf{m}^{3}\right)$ & Calcite & Kaolinite & Dolomite & Quartz & Ankerite & Siderite & Illite \\
\hline Low & 88 & 17,600 & 560 & 607 & 521 & 2008 & 2528 \\
High & 6446 & $2,298,400$ & 56,146 & 42,313 & 74,030 & 918,585 & $1,238,400$ \\
\hline
\end{tabular}

Table 2. Major minerals at the FWU and volume fractions [24].

\begin{tabular}{ccc}
\hline Mineral & Chemical Formula & Volume Fraction \\
\hline Quartz & $\mathrm{SiO}_{2}$ & $80.75 \%$ \\
Kaolinite & $\mathrm{Al}_{2} \mathrm{Si}_{2} \mathrm{O}_{5}(\mathrm{OH})_{4}$ & $6.76 \%$ \\
Siderite & $\mathrm{FeCO}_{3}$ & $4.41 \%$ \\
Calcite & $\mathrm{CaCO}_{3}$ & $3.86 \%$ \\
Illite & $\mathrm{K}_{0.6} \mathrm{Mg}_{0.25} \mathrm{Al}_{1.8}\left(\mathrm{Al}_{0.5} \mathrm{Si}_{3.5} \mathrm{O}_{10}\right)(\mathrm{OH})_{2}$ & $2.58 \%$ \\
Ankerite & $\mathrm{CaMg}_{0.3} \mathrm{Fe}_{0.7}\left(\mathrm{CO}_{3}\right)_{2}$ & $0.37 \%$ \\
Dolomite & $\mathrm{CaMg}_{\left(\mathrm{CO}_{3}\right)_{2}}$ & $0.01 \%$ \\
\hline
\end{tabular}

While choosing a value from the wide range for a certain mineral is already difficult, describing the changing characteristics of the mineral reactive surface area is no easier. The common practice in reactive transport simulations is to calculate the reactive surface area with the following equation:

$$
A_{i}=A_{i}^{0} \times \frac{N_{i}}{N_{i}^{0}}
$$

where $A_{i}$ is the reactive surface area of mineral $i$ at current time step, $A_{i}^{0}$ is the reactive surface area of mineral $i$ at time 0 (i.e., initial value), $N_{i}$ is the mole amount of mineral $i$ per unit grid block volume at the current time step, and $N_{i}^{0}$ is the mole amount of mineral $i$ per unit grid block volume at time 0 . There are two main restrictions on using this approach. Firstly, it assumes a uniform distribution of reactive surface area for the same mineral across the entire model domain (which could be kilometers for GCS sites); in other words, a homogenous reactive surface area is assigned to each mineral. Secondly, the controlling factor of reactive surface area at the current time step, $N_{i}$, is determined by the current mineral dissolution and precipitation rate that is affected by the mineral reactive surface area at previous time steps, as shown in Equation (2):

$$
r_{i}=A_{i} k_{i}\left(1-\frac{Q_{i}}{K_{e q, i}}\right),
$$

where $r_{i}$ is the reaction rate for mineral $i, k_{i}$ is the rate constant of mineral reaction $i, Q_{i}$ is the activity product of mineral reaction $i$, and $K_{e q, i}$ is the chemical equilibrium constant for mineral reaction $i$. Therefore, deviations between the estimated and real reactive surface areas accumulate over time and may lead to significantly different mineral reaction predictions after hundreds or thousands of years.

Given that an exhaustive dataset for the mineral reactive surface area is not available, and neither is an advanced reactive transport numerical model framework, an uncertainty 
analysis is probably the best approach to investigate the impact of mineral reactive surface area on GCS predictions. Based on the ranges listed in Table 1, a seven-factor Box-Behnken Design was developed to cover the entire uncertain space with 85 cases. The low $(-1)$, mid $(0)$, and high (+1) values for each of the seven minerals are presented in Figure 2. Please note that the mid values are not the average of the low and high values, but rather the median taken from the RSA values of the literature survey. Two more cases, $(-1,-1,-1)$ and $(+1,+1,+1)$, i.e., all low values and all high values, were added to the simulation design. A full list of the cases is presented in Table A1. It is anticipated that the design of these permutations will discover the impact of mineral reactive surface areas, with the mutual dependencies among the mineral reactions taken into account.

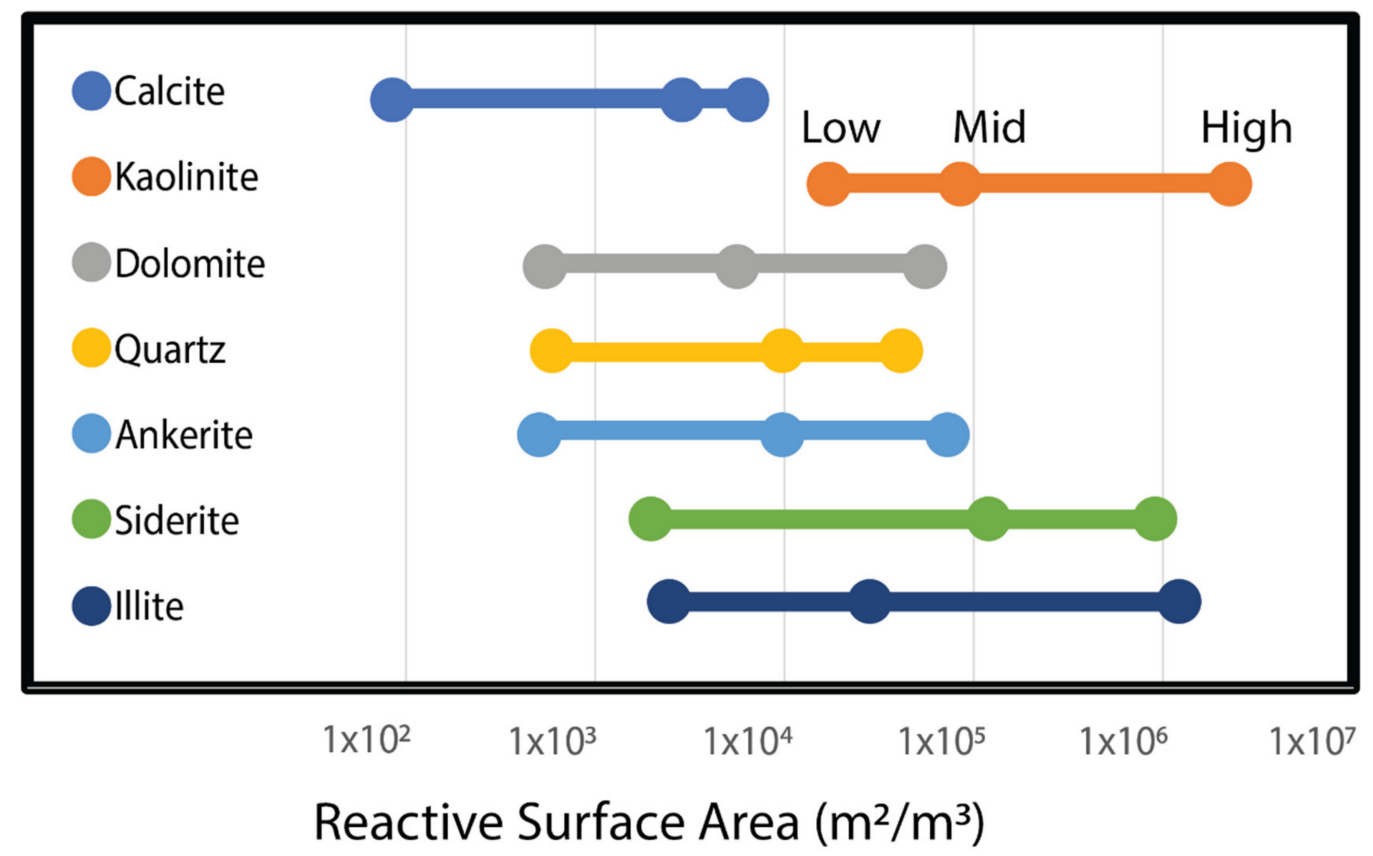

Figure 2. Low, mid, and high values of the reactive surface area of seven minerals.

\subsection{Numerical Models}

The 3D FWU reservoir model consists of 82 cells in the x-direction, 78 cells in the ydirection, and four cells in the $\mathrm{z}$-direction, with a total of 25,584 grid blocks. Each grid block is $200 \mathrm{ft}$ (or $60.96 \mathrm{~m}$ ) by $200 \mathrm{ft}$ (or $60.96 \mathrm{~m}$ ) in $\mathrm{x}$ and y directions and about $8.67 \mathrm{ft}$ (or $2.64 \mathrm{~m}$ ) in the z-direction. This model only includes the Morrow B sandstone, as the integrity of the overlying Thirteen Finger limestone will not be compromised for at least 5000 years [31]. A total of 55 wells (23 injectors and 32 producers) were distributed across the model domain in 5-spot patterns (Figure 1b). This reservoir model has been calibrated with the FWU field history by the SWP [34,42]. Well schedules include a 10-year $\mathrm{CO}_{2}$-EOR period, a subsequent 10 -year post-EOR $\mathrm{CO}_{2}$ injection period, and another 580-year monitoring period. In the $\mathrm{CO}_{2}$-EOR period, $\mathrm{CO}_{2}$ and water were alternatively injected (water alternating gas (WAG)), reflecting the site history. In the post-EOR $\mathrm{CO}_{2}$ injection period, all producers were shut-in, and $\mathrm{CO}_{2}$ was continuously injected at $5 \times 10^{6} \mathrm{ft}^{3} /$ day (or $1.42 \times 10^{5} \mathrm{~m}^{3} /$ day) through all injectors. In the monitoring period, all wells were shut-in, and no $\mathrm{CO}_{2}$ was injected into the model. The heterogeneous porosity and permeability distributions of the reservoir model were derived from the site characterization and geostatistical analysis of previous SWP work. Figure $1 \mathrm{~b}$ presents the heterogeneous porosity distribution of the 3D FWU model and the locations of the wells.

Seven major minerals were identified from FWU cores, as listed in Table 2. The measured volume fractions for each mineral are used as the initial conditions for the reservoir simulations. The SWP team periodically monitored the water quality of samples 
from the shallow aquifer and produced water collected at the FWU site. In this work, the averaged measurements of the produced water are used as the initial conditions of the aqueous species, as shown in Table 3. The compositions of hydrocarbon components were analyzed from FWU oil samples and are also listed in Table 3.

Table 3. Initial conditions of aqueous species and hydrocarbon components.

\begin{tabular}{cccc}
\hline Aqueous Species & $\begin{array}{c}\text { Molality } \\
(\mathbf{m o l} / \mathbf{k g ~ H} \mathbf{~} \mathbf{O})\end{array}$ & Hydrocarbon Components & Initial Global Composition \\
\hline $\mathrm{H}^{+}$ & $2.494 \times 10^{-7}$ & $\mathrm{C} 1$ & 0.405 \\
$\mathrm{~K}^{+}$ & $3.288 \times 10^{-6}$ & $\mathrm{C} 2$ & 0.038 \\
$\mathrm{Na}^{+}$ & $2.585 \times 10^{-2}$ & $\mathrm{C} 3$ & 0.024 \\
$\mathrm{Ca}^{2+}$ & $2.269 \times 10^{-5}$ & $\mathrm{IC} 4+\mathrm{NC} 4$ & 0.016 \\
$\mathrm{Mg}^{2+}$ & $2.930 \times 10^{-5}$ & $\mathrm{IC} 5+\mathrm{NC} 5$ & 0.027 \\
$\mathrm{SiO}_{2}(\mathrm{aq})$ & $5.640 \times 10^{-4}$ & $\mathrm{C} 6$ & 0.017 \\
$\mathrm{Fe}^{2+}$ & $1.598 \times 10^{-6}$ & $\mathrm{C}-\mathrm{C} 38$ & 0.325 \\
$\mathrm{Cl}^{-}$ & $1.379 \times 10^{-2}$ & $\mathrm{C} 38-\mathrm{C} 70$ & 0.147 \\
$\mathrm{OH}^{-}$ & $6.354 \times 10^{-7}$ & $\mathrm{CO}_{2}$ & 0.001 \\
$\mathrm{HCO}_{3}^{-}$ & $3.720 \times 10^{-2}$ & & \\
$\mathrm{CO}_{3}^{2-}$ & $1.190 \times 10^{-5}$ & & \\
\hline
\end{tabular}

Seven mineral reactions and three aqueous reactions were modeled in this work, as shown in Table 4 . The chemical equilibrium constants $\left(\log K_{\text {eq }}\right)$ were calculated for reservoir temperature at $70{ }^{\circ} \mathrm{C}$ with the EQ3/6 database [43], and the activation energy and the standard TST rate constant $\left(\log k_{25^{\circ} \mathrm{C}}\right)$ values were taken from Palandri and Kharaka (2004) [44]. In particular, fourth-order polynomials were fitted to the EQ3/6 database of chemical equilibrium constants of the reactions versus temperature (please see Figure A1).

Table 4. Mineral and aqueous reactions and parameters for reactive transport modeling [43,44].

\begin{tabular}{cccc}
\hline Reaction & Activation Energy $\mathbf{( k J / m o l )}$ & $\log \boldsymbol{K}_{\boldsymbol{e q}}$ at $70{ }^{\circ} \mathbf{C}$ & $\mathbf{l o g} \boldsymbol{k}_{25^{\circ} \mathbf{C}}\left(\mathbf{m o l} / \mathbf{m}^{2} \mathbf{s}\right)$ \\
\hline Calcite $+\mathrm{H}^{+}=\mathrm{Ca}^{2+}+\mathrm{HCO}_{3}^{-}$ & 41.87 & 1.192 & -5.810 \\
Kaolinite $+6 \mathrm{H}^{+}=5 \mathrm{H}_{2} \mathrm{O}+2 \mathrm{SiO}_{2}(\mathrm{aq})+2 \mathrm{Al}^{3+}$ & 62.76 & 3.103 & -13.180 \\
Dolomite $+2 \mathrm{H}^{+}=\mathrm{Ca}^{2+}+\mathrm{Mg}^{2+}+2 \mathrm{HCO}_{3}^{-}$ & 73.75 & 2.278 & -8.065 \\
Quartz $=\mathrm{SiO}_{2}(\mathrm{aq})$ & 89.09 & -3.345 & -13.680 \\
Ankerite $=\mathrm{Ca}^{2+}+0.95 \mathrm{Fe}^{2+}+0.05 \mathrm{Mg}^{2+}+2 \mathrm{CO}_{3}^{2-}$ & 62.76 & -125 & -8.900 \\
Siderite $+\mathrm{H}^{+}=\mathrm{Fe}^{2+}+\mathrm{HCO}_{3}^{-}$ & 62.76 & -1.001 & -8.900 \\
$\mathrm{Illite}+8.0 \mathrm{H}^{+}=$ & 35.00 & -1.677 & -12.780 \\
$0.25 \mathrm{Mg}^{2+}+0.6 \mathrm{~K}^{+}+2.3 \mathrm{Al}^{3+}+3.5 \mathrm{SiO}_{2}(\mathrm{aq})+5.0 \mathrm{H}_{2} \mathrm{O}$ & - & -13.263 & - \\
$\mathrm{H}_{2} \mathrm{O}=\mathrm{H}^{+}+\mathrm{OH}^{-}$ & -6.322 & - \\
$\mathrm{CO}_{2}+\mathrm{H}_{2} \mathrm{O}=\mathrm{H}^{+}+\mathrm{HCO}_{3}^{-}$ & - & -16.556 & - \\
$\mathrm{CO}_{2}+\mathrm{H}_{2} \mathrm{O}=2 \mathrm{H}^{+}+\mathrm{CO}_{3}^{2-}$ & - & \\
\hline
\end{tabular}

Reactive transport models require more computational resources than multiphase flow models because of the additional governing equations for aqueous and mineral reactions. Therefore, simplified modes are often used for reactive transport simulations. A similar approach was followed in this work. Instead of using the abovementioned reservoir model for all 87 simulations, a screening study was conducted first, which used a simplified 3D model to evaluate the performances of all 87 combinations of mineral reactive surface areas. Then the selected combinations, which are either representative or extreme scenarios, were repeated with the full FWU reservoir model. The simplified 3D model effectively represents a batch simulation. In particular, there are three cells in each direction $(x, y$, and $\mathrm{z}$ ), with infinite acting aquifers around all boundaries to avoid the boundary effect. A $\mathrm{CO}_{2}$ injection well was placed in the center of the model to introduce supercritical $\mathrm{CO}_{2}$ to the model at a bottom-hole pressure constrained injection rate. Except for the grid structure and well configurations, all other model settings are identical to the full-size reservoir model. Simulation results at the center of this simplified model can be used to 
screen the combinations of mineral reactive surface areas. In addition to the much lower computational cost, the other advantage of this approach is that it can isolate control factors to simulation results, e.g., the domain size and the interference of multiple wells, and therefore focus on discovering the impact of mineral reactive surface area.

All simulations were performed with the 2019.10 version of the CMG-GEM simulation package, the flow equations of which are listed in Appendix B.

\section{Results}

\subsection{Screening the RSA Combinations}

The 87 combinations were simulated to study the ranges of uncertainty in mineral precipitation/dissolution and $\mathrm{CO}_{2}$ mineral trapping caused by using different mineral RSA values. Figures 3 and 4 present the simulation results of the simplified model and emphasize three RSA combinations, Case \#85, Case \#86, and Case \#87, where all mineral RSA values were set at mid, low, and high, respectively (please refer to Table A1 for the detailed RSA combinations). The predicted $\mathrm{pH}$ values of all cases exhibit a similar pattern (Figure 3a). A drastic drop from the initial $\mathrm{pH}(\sim 6.7)$ to the range of $4.0 \sim 4.4$ during the first day is followed by a relatively slower recovery through the rest of the simulation period. While most of the curves overlap each other, the dashed dark green line, which indicates the results of Case \#86, presents a deeper $\mathrm{pH}$ decrease in the beginning and a slower $\mathrm{pH}$ recovery rate. Comparing the much faster $\mathrm{pH}$ recovery rate of the other cases, it is obvious that the prolonged recovery time of Case \#86 results from the lack of buffers, i.e., fewer accessible minerals to react with the $\mathrm{H}^{+}$introduced by $\mathrm{CO}_{2}$.
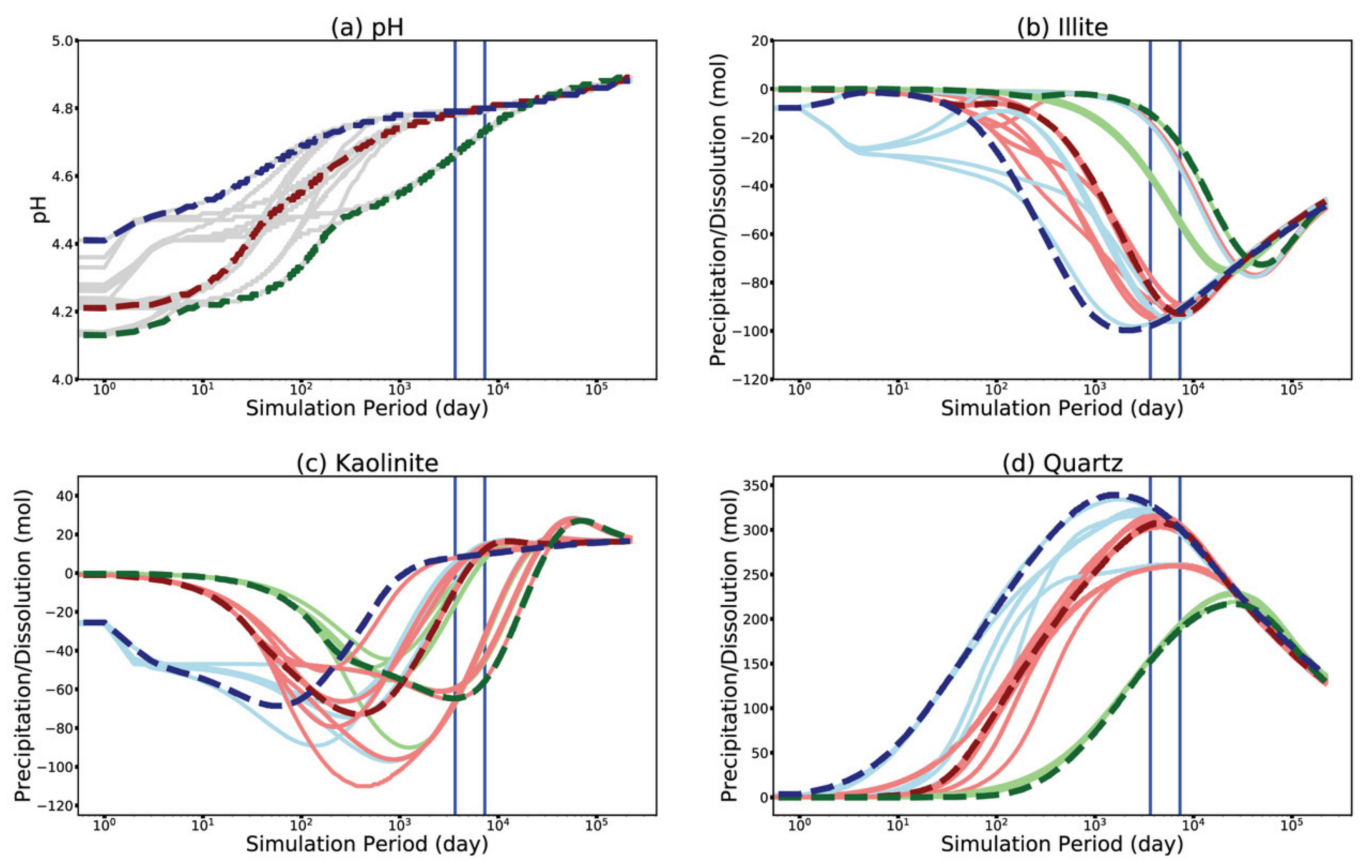

Figure 3. (a) Predicted $\mathrm{pH}$ and mineral precipitation or dissolution of (b) illite, (c) kaolinite, and (d) quartz at the center of the model. Light green, light red, and light blue indicate low, mid, and high RSA of the particular mineral in each subplot; dashed lines in dark green, dark red, and dark blue indicate cases with all low RSA (Case\#86), all mid RSA (Case \#85), and all high RSA (Case \#87), respectively; two vertical lines denotes the end of 10 years and the end of 20 years. 
(a) Ankerite

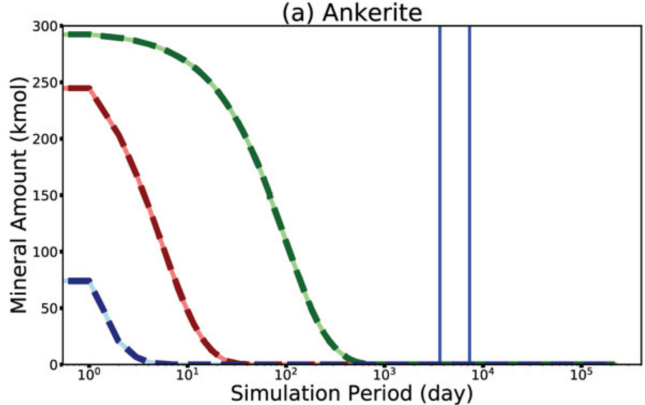

(c) Siderite

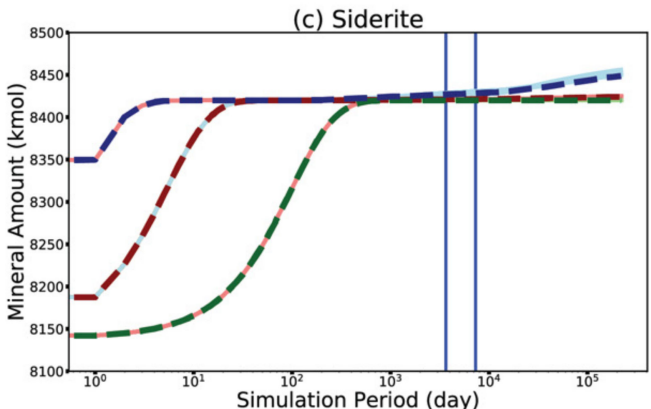

(b) Calcite

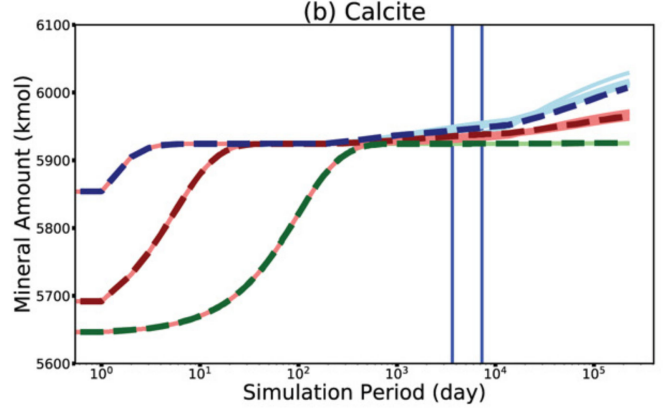

(d) Dolomite

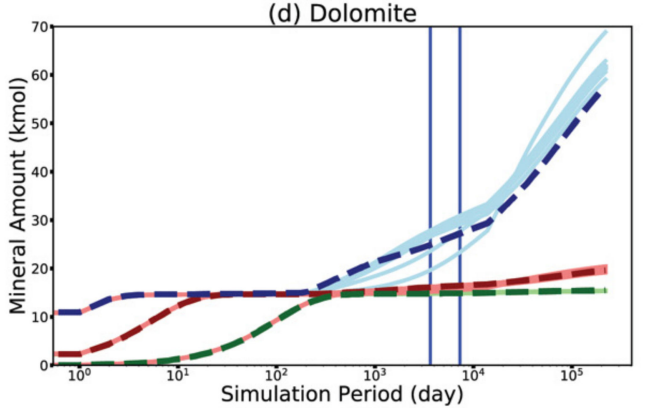

Figure 4. Predicted total mineral amount in the simplified model for (a) ankerite, (b) calcite, (c) siderite, and (d) dolomite. Light green, light red, and light blue indicate low, mid, and high RSA of the particular mineral in each subplot; dashed lines in dark green, dark red, and dark blue indicate Case\#86, Case \#85, and Case \#87, respectively; two vertical lines denote the end of 10 years and the end of 20 years.

Because the changes of the silicate minerals are much smaller than the total amount of silicate minerals in the model, the mineral reaction rate is a better parameter to illustrate the silicate mineral reactions. The predicted precipitation or dissolution of silicates at the center of the model are shown in Figure 3b-d. For illite and quartz, Case \#87 (dashed dark blue line) and Case \#86 (dashed dark green line) is the most and the least reactive scenario for these two minerals, whereas Case \#85 (dashed dark red line) overlaps with most of the medium cases. On the other hand, changes in kaolinite are more complicated. There are many crossovers and overlaps among results using different kaolinite RSA values, and the deviations between lines in the same color are much greater than those in Figure $3 b$ or Figure $3 \mathrm{~d}$. This suggests that the reaction of kaolinite is controlled by not only the RSA of kaolinite but also the RSA of other minerals. Nevertheless, the high RSA cases (blue) predicted prompt and more intense reactions, while the low RSA cases (green) predicted delayed and more restricted reactions.

The simulation results of four carbonate minerals, ankerite, calcite, siderite, and dolomite, are shown in Figure $4 \mathrm{a}-\mathrm{d}$, respectively. Please note that all 87 cases started with the same initial mineral amounts, and Figure 4 presents mineral amounts since Day 1; therefore, the differences between the starting points of the lines in each subplot indicate the difference in the reactions that occurred during the first day of simulation. For example, the total amount of ankerite in the model was initially about $295 \mathrm{kmol}$, and dropped to $74 \mathrm{kmol}$ in Case \#87 (dashed dark blue line), whereas it dropped to about $245 \mathrm{kmol}$ in Case \#85 (dashed dark red line) and to $292 \mathrm{kmol}$ in Case \#86 (dashed dark green line), after the first day of simulation.

For all 87 cases, a monotonic dissolution of ankerite is observed, while all three other minerals show monotonic precipitation within the 600 years of simulation. The low RSA cases (green lines) once again exhibit the least reactivity, i.e., the slowest to deviate from the initial values. Interestingly, the prediction results fall into three clusters for each of these four minerals in the first year. In other words, the RSA value of the particular mineral, being either low, mid, or high, determines the reaction of this mineral in the first year, 
regardless of what RSA values are used for the other six minerals. Moreover, there is zero or small difference among predicted mineral amounts using the three levels of RSA values for ankerite (Figure 4a) and siderite (Figure 4c) in the later stage of the simulation period. The differences among the three clusters of lines are more obvious for calcite (Figure $4 \mathrm{~b}$ ) and dolomite (Figure $4 \mathrm{~d}$ ) after 300 days. At the end of the simulations, the cases with the high dolomite RSA value forecast much greater dolomite precipitation than the other cases.

Compared to the silicate minerals (Figure $3 b-d$ ), a stronger clustering effect is observed in the carbonate minerals, especially in the first two years of simulation, suggesting that the reaction of the carbonate mineral (Figure $4 \mathrm{a}-\mathrm{d}$ ) is more controlled by its own RSA value. The interference (or mutual dependence) between mineral reactions is weaker for the carbonate minerals than for the silicate minerals. As a result, Cases \#85, \#86, and \#87 seem to be able to represent the median, minimum, and maximum reaction scenarios of all tested cases for all minerals.

The mineral trapping of $\mathrm{CO}_{2}$ in the simplified model was evaluated with all 87 cases, and the results are presented in Figure 5. There is a much greater deviation among total mineral trapping amount predictions than the predictions for each mineral, as shown in Figures 3 and 4. No clear clustering is observed in Figure 5. While the impact of RSA on each individual mineral is apparent and easier to interpret, its impact on the $\mathrm{CO}_{2}$ trapping mechanism is rather complicated. This is likely due to the different abilities of each mineral to sequester $\mathrm{CO}_{2}$. For example, one mole of precipitated calcite effectively secures one mole of $\mathrm{CO}_{2}$, while for dolomite the ratio becomes 1:2. At the end of the simulation, the amount of $\mathrm{CO}_{2}$ trapped in the minerals ranges from $2 \mathrm{kmol}$ to $200 \mathrm{kmol}$. The results of three representative cases (\#86, \#86, and \#87) are very close to the median, minimum, and maximum values of all cases, as shown in the dashed lines in Figure 5. Therefore, these cases were selected for reactive transport simulations with the FWU reservoir model.

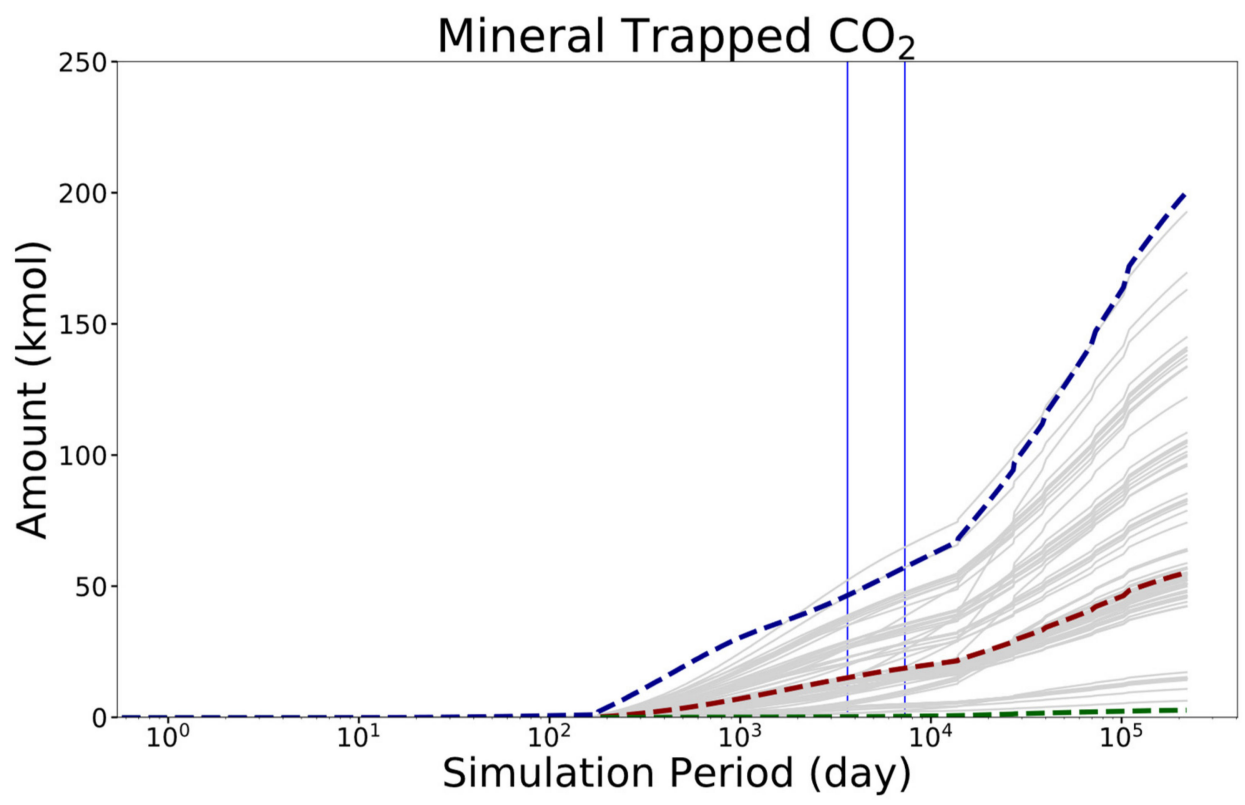

Figure 5. The predicted amount of mineral trapped $\mathrm{CO}_{2}$ in the simplified $3 \mathrm{D}$ model. Dashed lines in dark green, dark red, and dark blue indicate Case\#86, Case \#85, and Case \#87, respectively; gray lines denote all other cases, and two vertical lines denote the end of 10 years and the end of 20 years.

\subsection{Reactive Transport Prediction with the Reservoir Model}

As minerals precipitate or dissolve, it can change the porosity of the storage formation and thus affect fluid flow patterns and subsequent mineral reactions at new fluid-rock contacts. Therefore, we analyzed the porosity change due to mineral reactions in the FWU model. Figures 6-8 present the changes in porosity at three critical time steps: the end of 
the $\mathrm{CO}_{2}$-EOR period, the end of the post-EOR $\mathrm{CO}_{2}$ injection period, and the end of the simulation period, respectively.
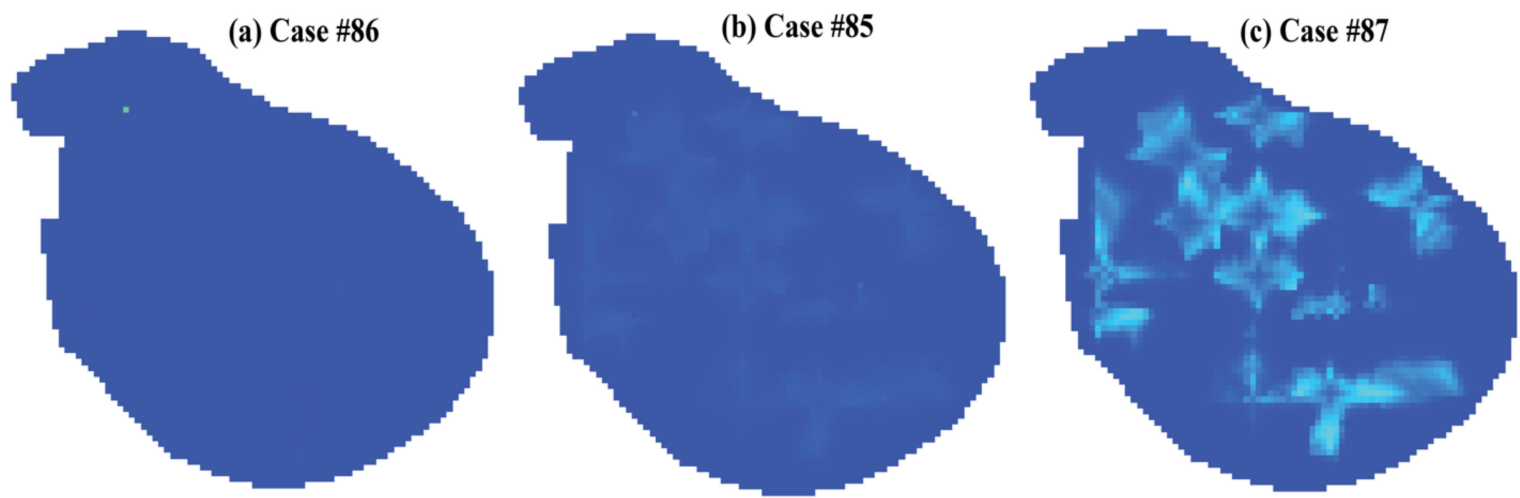

Porosity Change

$0.0 \times 10^{-3} \quad 0.5 \times 10^{-3} 1.0 \times 10^{-3} 1.5 \times 10^{-3} 2.0 \times 10^{-3} 2.5 \times 10^{-3} 3.0 \times 10^{-3} 3.5 \times 10^{-3} 4.0 \times 10^{-3} 4.5 \times 10^{-3} 5.0 \times 10^{-3} 5.5 \times 10^{-3} 6.0 \times 10^{-3} 6.5 \times 10^{-3} 7.0 \times 10^{-3}$

Figure 6. Estimated porosity loss at the end of the $\mathrm{CO}_{2}-\mathrm{EOR}$ period compared to the initial values for (a) Case \#86, (b) Case \#85, and (c) Case \#87.
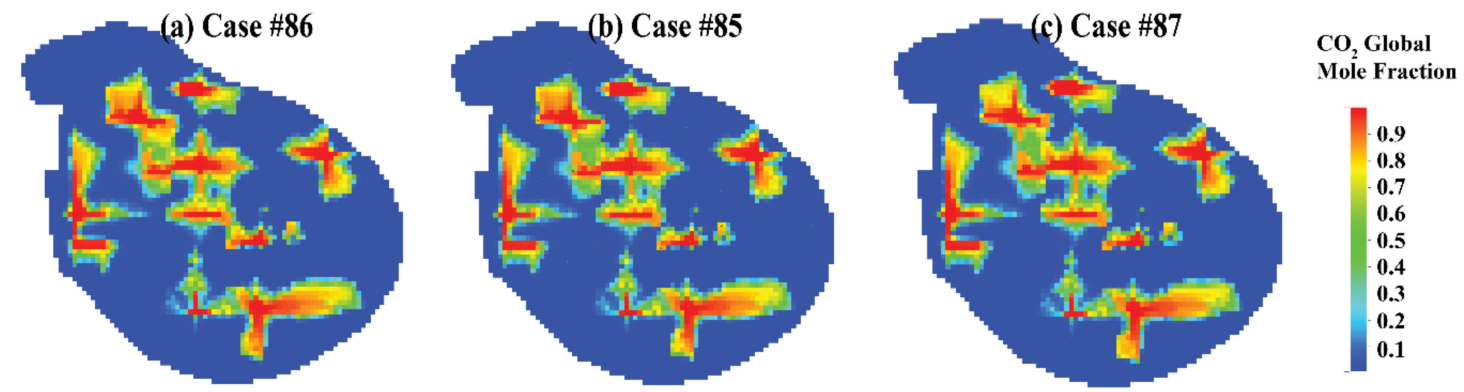

Figure 7. Simulated $\mathrm{CO}_{2}$ global mole fraction at the end of the $\mathrm{CO}_{2}-\mathrm{EOR}$ period for (a) Case \#86, (b) Case \#85, and (c) Case \#87.
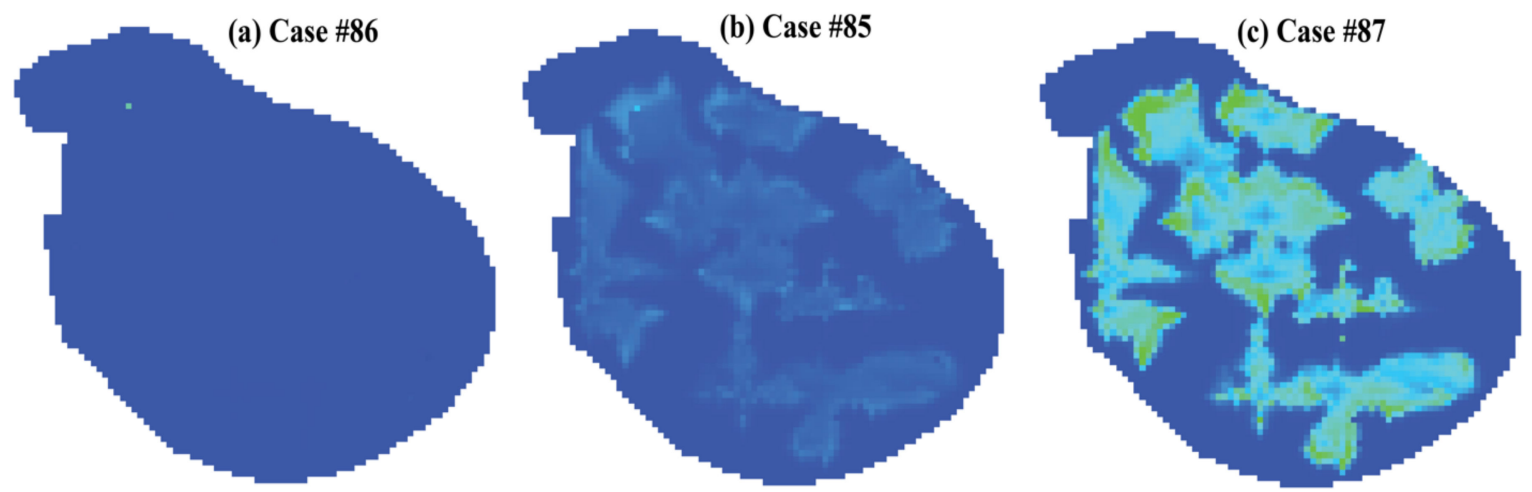

Porosity Change

$0.0 \times 10^{-3} 0.5 \times 10^{-3} 1.0 \times 10^{-3} 1.5 \times 10^{-3} 2.0 \times 10^{-3} 2.5 \times 10^{-3} 3.0 \times 10^{-3} 3.5 \times 10^{-3} 4.0 \times 10^{-3} 4.5 \times 10^{-3} 5.0 \times 10^{-3} 5.5 \times 10^{-3} 6.0 \times 10^{-3} 6.5 \times 10^{-3} 7.0 \times 10^{-3}$

Figure 8. Estimated porosity loss at the end of the post-EOR $\mathrm{CO}_{2}$ injection period compared to the initial values for (a) Case \#86, (b) Case \#85, and (c) Case \#87.

After ten years of $\mathrm{CO}_{2}$-EOR operation, porosity reduction is observed in all three cases. Figure 6 shows changes of porosity due to mineral reactions at the top layer of the Morrow B sandstone using the RSA values of Case \#86 (all low RSA values of seven minerals), Case \#85 (all mid RSA values), and Case \#87 (all high RSA values), respectively. In general, 
a dominant porosity reduction was observed for all cases. Specifically, Case \#86 (Figure 6a) exhibits the most restricted variation, while Case \#87 (Figure 6c) presents the greatest porosity change across the layer, showing a maximum porosity reduction of $1.86 \times 10^{-3}$ (or $0.9 \%$ of the initial porosity). However, very similar $\mathrm{CO}_{2}$ global mole fraction distributions were predicted by three models (Figure 7). This suggests that the mineral reactions have an insignificant impact on the $\mathrm{CO}_{2}$ migration. Given that the $\mathrm{CO}_{2}$ plume shapes are mostly identical among the three cases, the difference in porosity change is attributed to the mineral RSA values.

The $\mathrm{CO}_{2}$-EOR period was followed by a post-EOR $\mathrm{CO}_{2}$ injection period, during which all production wells were shut-in, and $\mathrm{CO}_{2}$ was continuously injected via all injection wells for ten years. Figure 7 presents the simulation results of porosity changes due to mineral reactions. There are visible changes in porosity reduction comparing Figures $8 \mathrm{~b}$ and $6 \mathrm{~b}$, and Figures $8 \mathrm{c}$ and $6 \mathrm{c}$. A clear expansion of areas with porosity loss is observed. The greater porosity reductions occur along the edges of the $\mathrm{CO}_{2}$ plumes (Figure 8c). Specifically, after ten years of $\mathrm{CO}_{2}$ injection, the maximum porosity loss has been increased to $0.7 \%$ in Case \#85 and 2.5\% in Case \#87, from $0.3 \%$ and $0.9 \%$, respectively. However, the $\mathrm{CO}_{2}$ flow patterns are still almost identical for all three cases (figure not shown). Therefore, the impact of mineral reactions on $\mathrm{CO}_{2}$ flow remains insignificant during the post-EOR $\mathrm{CO}_{2}$ injection period.

Figure 9 presents the estimated porosity loss at the end of the 600-year simulation period. The simulation results of using all low RSA values present almost no change in porosity due to mineral reactions (Figure 9a). On the other hand, using all mid and high RSA values leads to greater porosity reduction, as shown in Figure 9b,c. While there is only a slight expansion of porosity loss areas during the no-injection period, the maximum porosity loss due to mineral reactions increased to $1.19 \%$ and $5.04 \%$ for Case \#85 and Case \#87, respectively. It is worth noting that the predicted porosity changes in Figures $6 c$ and $8 c$ are more profound than those in Figure 9a,b, suggesting that using high RSA values leads to dramatically different porosity change predictions, hence mineral trapping of $\mathrm{CO}_{2}$, over even a short time period. Comparing the distributions of $\mathrm{CO}_{2}$ global mole fraction (Figure 10) and porosity change (Figure 9), it is clear that the mineral reactions had a nominal impact on the forecast of $\mathrm{CO}_{2}$ migration in 600 years. It is interesting to note that there are lower porosity changes in the centers of the $\mathrm{CO}_{2}$ plumes, where they exhibit very high (greater than 0.8) $\mathrm{CO}_{2}$ global mole fractions (see Figures 7 and 10). The areas with greater porosity reduction are located on the edges (or fronts) of the $\mathrm{CO}_{2}$ plumes, suggesting that there are more intense geochemical reactions and thus more $\mathrm{CO}_{2}$ trapped in minerals or aqueous ions. This is because mineral reactions require sufficient contacts between the minerals and the formation fluids, which is less likely to be present in areas with very high $\mathrm{CO}_{2}$ saturation.
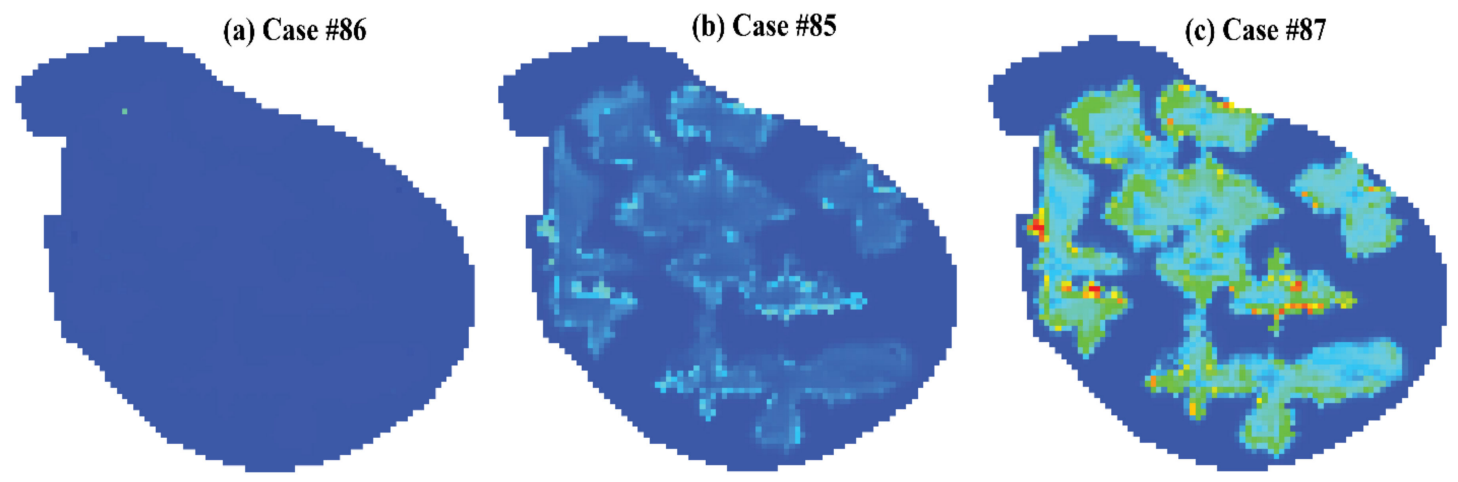

Porosity Change

$0.0 \times 10^{-3} \quad 0.5 \times 10^{-3} 1.0 \times 10^{-3} 1.5 \times 10^{-3} 2.0 \times 10^{-3} 2.5 \times 10^{-3} 3.0 \times 10^{-3} 3.5 \times 10^{-3} 4.0 \times 10^{-3} 4.5 \times 10^{-3} 5.0 \times 10^{-3} 5.5 \times 10^{-3} 6.0 \times 10^{-3} 6.5 \times 10^{-3} 7.0 \times 10^{-3}$

Figure 9. Estimated porosity loss at the end of the simulation period compared to the initial values for (a) Case \#86, (b) Case \#85, and (c) Case \#87. 

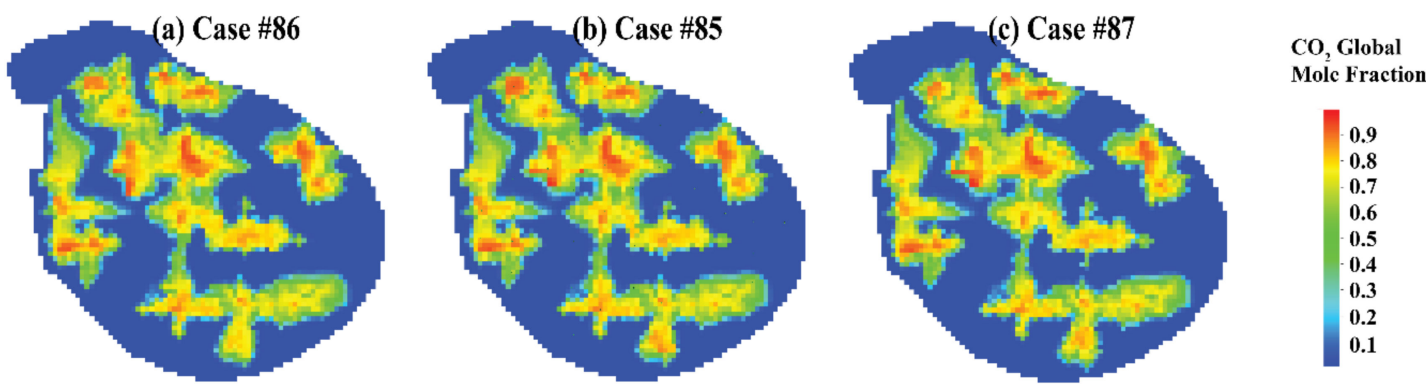

Figure 10. Simulated $\mathrm{CO}_{2}$ global mole fraction at the end of the simulation period for (a) Case \#86, (b) Case \#85, and (c) Case \#87.

The performance of trapping mechanisms that are directly related to the geochemical reactions was evaluated, as shown in Figure 11. As expected, and similar to the simplified model result (Figure 5), there is a significant difference between the amount of $\mathrm{CO}_{2}$ trapped in minerals in the FWU field-scale reservoir model (Figure 11a). The mineral trapping first appeared as early as about 200 days (for Case \#87), accelerated during the postEOR $\mathrm{CO}_{2}$ injection period (between the two vertical blue lines), and kept growing at a slower rate after $\mathrm{CO}_{2}$ injection stopped. At the end of 600 years, the estimated amounts of $\mathrm{CO}_{2}$ trapped in minerals are $3.25 \times 10^{6} \mathrm{kmol}\left(1.43 \times 10^{5}\right.$ metric tons $), 0.8 \times 10^{6} \mathrm{kmol}$ ( $3.52 \times 10^{4}$ metric tons), and $0.05 \times 10^{6} \mathrm{kmol}\left(2.2 \times 10^{3}\right.$ metric tons) for Case \#87, Case \#85, and Case \#86, respectively. In other words, mineral trapping with all high RSA values is about four times more effective than with all mid RSA values, and 65 times more effective than with all low RSA values. At the end of 600 years, mineral trapping would contribute to $0.15 \%, 2.46 \%$, and $9.44 \%$ of the total sequestered $\mathrm{CO}_{2}$ at the FWU when using the low, mid, and high mineral RSA values, respectively. However, the mineral RSA values have much less impact on the $\mathrm{CO}_{2}$ trapped in aqueous ions (Figure 11b). The maximum difference between predictions is only about $0.02 \times 10^{6} \mathrm{kmol}$ (880 metric tons), and only $0.12 \times 10^{6} \mathrm{kmol}\left(5.28 \times 10^{3}\right.$ metric tons) of $\mathrm{CO}_{2}$ was sequestered in aqueous ions by the end of the simulation. Nevertheless, mineral reactions and aqueous ions are able to sequester at least around 3000 metric tons of $\mathrm{CO}_{2}$ (in Case \#86), which would be otherwise presented in other forms (i.e., supercritical phase or dissolved) if reactive transport was not taken into consideration.
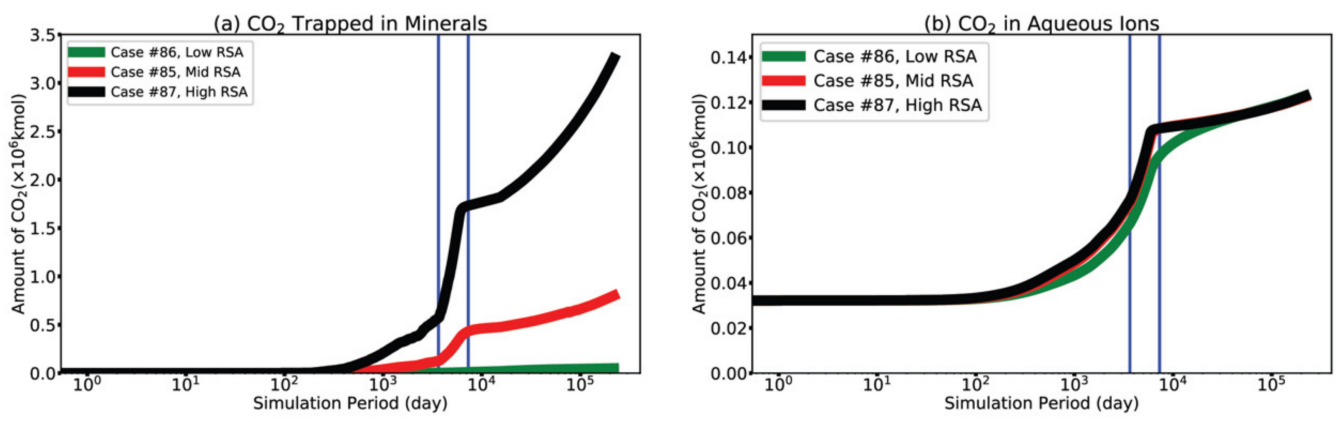

Figure 11. Performance comparison of (a) $\mathrm{CO}_{2}$ mineral trapping and (b) $\mathrm{CO}_{2}$ trapped in aqueous.

\section{Discussion}

Geochemical reactions, especially mineral reactions, are critical in predicting the fate and behavior of injected $\mathrm{CO}_{2}$ into the subsurface and are involved in many aspects of a GCS project, such as the risk assessment of $\mathrm{CO}_{2}$ leakage and caprock integrity. While most reactive transport studies were focused on $\mathrm{CO}_{2}$ storage in deep saline aquifers, only a few incorporated the geochemical module into their simulations for $\mathrm{CO}_{2}$ storage in depleted oil fields. Possible reasons for this could include: (1) mineral reactions in a depleted oil field are assumed to be similar to those in a deep saline aquifer, but in a much-restricted 
approach because of the presence of hydrocarbons; (2) the mineral trapping at depleted oil fields is considered to be less effective than other trapping mechanisms in a short period of time, thus it can be ignored for the purpose of storage estimation; and (3) most $\mathrm{CO}_{2}$ storage numerical simulation packages are incapable of simulating reactive transport in three-phase systems (oil/water/ $\mathrm{CO}_{2}$ ). The results of this work demonstrate that neither the porosity reduction due to mineral reactions nor the mineral trapping of $\mathrm{CO}_{2}$ at a $\mathrm{CO}_{2}$-EOR field is negligible. Using the mid RSA values of all seven minerals, up to $0.7 \%$ of porosity loss was forecasted after 20 years of $\mathrm{CO}_{2}$ injection, and up to $1.19 \%$ of porosity loss was forecasted after 600 years. This is similar to the porosity change estimated by Pan et al., 2016 , which reported up to $0.7 \%$ of porosity reduction and up to $2.7 \%$ of porosity increase after 1000 years due to mineral reactions [45]. In that work, a modified FWU model was used, where there was only one five-spot well pattern and a deep saline storage scenario had been adopted (i.e., no hydrocarbon in the model). Nevertheless, similar results in estimated porosity change suggest that mineral reactions in three-phase systems probably are not as limited as it is assumed.

We have performed a preliminary study comparing the differences of mineral reactions in two-phase (Figures A2 and A3) and three-phase systems (Figures 3 and 4) using the simplified 3D model. When hydrocarbon components were replaced with water, different predictions were found in most minerals. While the changes of illite and quartz slowed down in the monitoring period and tended to recover to the initial values in the threephase models, the dissolution of illite and precipitation of quartz in the two-phase model was accelerated. Moderate differences were observed in the carbonate minerals. In the two-phase models, an equilibrium state was reached during the first year of $\mathrm{CO}_{2}$ injection and maintained throughout the entire simulation period (Figure A3), leading to almost no $\mathrm{CO}_{2}$ being trapped in minerals (Figure 12); however, the three-phase models predicted that more carbonate minerals would precipitate in the monitoring period (Figure 4), which would then result in a significant amount of $\mathrm{CO}_{2}$ being present in the minerals (Figure 5). There is a clear impact of the presence of hydrocarbons on mineral reactions with this simplified model. Therefore, the assumption that the mineral reactions in three-phase systems are only a scaled-down version of those in two-phase systems is not necessarily correct. When considering the interactions between hydrocarbon components and minerals and aqueous species (which are not incorporated in this work), it would be inevitable to develop a new paradigm for the reactive transport modeling of $\mathrm{CO}_{2}$ storage in depleted oil fields.

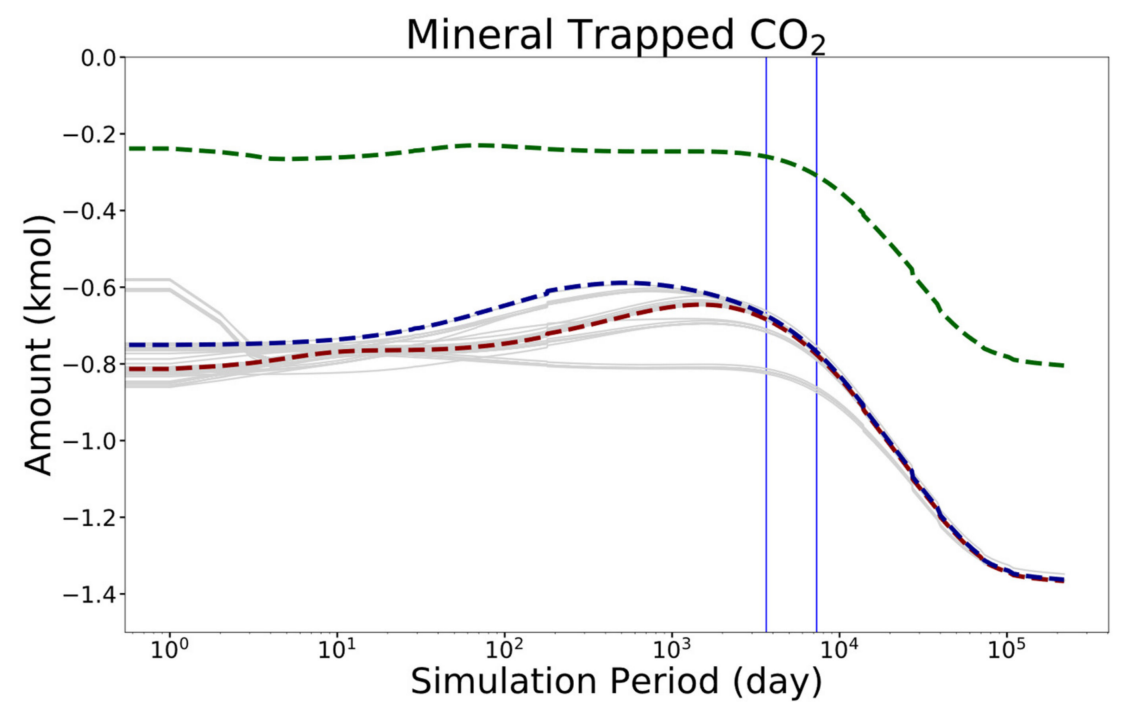

Figure 12. The predicted amount of mineral trapped $\mathrm{CO}_{2}$ in the simplified $3 \mathrm{D}$ model with hydrocarbons removed. Dashed lines in dark green, dark red, and dark blue indicate Case\#86, Case \#85, and Case \#87, respectively; two vertical lines denote the end of 10 years and the end of 20 years. 
In order to identify and quantify the roles of mineral RSA, many other important factors were fixed in this work. The simulation results will be affected by varying these factors, which include geological and hydrogeological properties (e.g., porosity and permeability values), multiphase flow models (e.g., relative permeability, hysteresis, and capillary pressure models), and operational factors (e.g., well spacing and depths, well operational limits, and $\mathrm{CO}_{2}$-EOR and WAG configurations). The impacts of mineral RSA will also be subject to other site-specific conditions when transferring the specific findings of this work to other case studies. However, it is believed that the importance of mineral RSA and the necessity of adding reactive transport modeling to $\mathrm{CO}_{2}-\mathrm{EOR}$ simulations are applicable to other GCS projects.

Additionally, reactive transport modeling is an indispensable component in understanding and mastering the coupled thermal-hydro-mechanical-chemical (THMC) processes in the subsurface porous media [46-48]. A thorough investigation of mineral RSA is vital for coupling mineral reactions with other critical subsurface phenomena, for example, mechanical and thermal deformation. On the other hand, the thermal and mechanical in situ conditions will affect mineral reactions on the whole. Given the capability of existing simulation tools, improvements in geochemical modeling and a better coupling of THMC processes are in urgent need. The geochemical properties should be treated the same as the flow or reservoir properties (e.g., porosity, permeability, pressure, saturation, etc.). The heterogeneity in mineral distributions and the temporal evolution of mineral properties should be incorporated into the reactive transport modeling. This work employed 87 combinations of mineral RSA values as a workaround to take both spatial and temporal variations in mineral RSA into account. While this approach has been effective in showing the impact of mineral RSA values on mineral reactions, it does not demonstrate the geochemical-hydrological coupling effect primarily due to the fact that the uniform distribution of mineral compositions across the model inhibits the ability of mineral reactions to affect the fluid flow. With the recent advances in RSA measurement techniques, it is vital to make better use of lab observations in numerical simulations for more accurate predictions. The absence of the geochemical-hydrological coupling effect could also be attributed to the spatial resolution ( $200 \mathrm{ft}$, or $60.96 \mathrm{~m}$ ) of the numerical model employed in this work, which might be too coarse to capture reactions and fluid flow at small-scales (from centimeter to meter). Even with paralleled high-performance computing nodes, each of the 600-year simulations on the model with 200 -ft resolution took more than eight hours. Refining the spatial resolution will no doubt increase the computational cost significantly, and very likely cause numerical convergence issues as the reservoir heterogeneity will be more complicated after adding more small-scale local geological features. Moreover, obtaining a reasonable down-scaled heterogeneity renders its own challenges and will be tackled in our future research.

\section{Conclusions}

In this work, the impact of mineral reactive surface areas on the $\mathrm{CO}_{2}$ storage forecast was evaluated for the GCS project in the Farnsworth Unit in northern Texas. In order to reduce the computational cost, a simplified 3D model was used to screen representative RSA combinations from 87 cases. Three cases were chosen for the FWU reactive transport simulation. The main conclusions are drawn as follows:

(1) The inter-dependency effects of mineral RSA values are stronger in the silicate mineral reactions and almost not observed in the carbonate mineral reactions;

(2) The impact of mineral RSA values on $\mathrm{CO}_{2}$ mineral trapping, on the whole, is more complex than it is on individual geochemical reactions. However, the three selected cases (with all low, all mid, and all high mineral RSA values) are representative for predicting $\mathrm{CO}_{2}$ trapped in minerals; 
(3) While the low RSA case predicted negligible porosity change and an insignificant amount of $\mathrm{CO}_{2}$ mineral trapping for the FWU model, the mid and high RSA cases forecasted up to $1.19 \%$ and $5.04 \%$ of porosity reduction due to mineral reactions, and $2.46 \%$ and $9.44 \%$ of total $\mathrm{CO}_{2}$ trapped in minerals by the end of the 600 -year simulation, respectively;

(4) The presence of hydrocarbons affects geochemical reactions and can lead to net $\mathrm{CO}_{2}$ mineral trapping, whereas negative $\mathrm{CO}_{2}$ mineral trapping is forecasted when hydrocarbons are removed from the system.

Author Contributions: Methodology, W.J. and T.X.; investigation, W.J. and T.X.; resources, Z.W. and Z.D.; supervision, B.M.; writing-original draft preparation, W.J.; writing-review and editing, all authors. All authors have read and agreed to the published version of the manuscript.

Funding: Funding for this project was provided by the U.S. Department of Energy's (DOE) National Energy Technology Laboratory (NETL) through the Southwest Regional Partnership on Carbon Sequestration (SWP) under Award No. DE-FC26-05NT42591.

Data Availability Statement: Publicly available datasets were analyzed in this study. This data can be found here: https:/ / edx.netl.doe.gov/group/rcsp-swp (accessed on 7 February 2021).

Conflicts of Interest: The authors declare no conflict of interest.

\section{Nomenclature}

$\begin{array}{ll}D & \text { Depth } \\ n_{c} & \text { Number of components } \\ N_{i} & \text { Moles of Component } i \text { per unit of gridblock volume } \\ N_{n_{c}+1} & \text { Moles of water per unit of gridblock volume } \\ p & \text { Pressure } \\ P_{c o g} & \text { Oil-gas capillary pressure } \\ P_{c w o} & \text { Water-oil capillary pressure } \\ q & \text { Injection/production rate } \\ t & \text { Time } \\ T_{j} & \text { Transmissibility of phase } j \\ V & \text { Gridblock volume } \\ y_{i j} & \text { Mole fraction of Component } i \text { in phase } j \\ \gamma & \text { Specific gravity } \\ \Delta t & \text { Timestep } \\ \rho_{m} & \text { Molar density of phase } m \\ \phi & \text { Porosity } \\ \psi & \text { Function } \\ \text { Superscripts } & \\ (k) & \text { Iteration level } \\ n & \text { Old time level } \\ n+1 & \text { New time level } \\ \text { Subscripts } & \\ i & \text { component } \\ j & \text { phase } \\ o & \text { oil } \\ g & \text { gas } \\ w & \text { water }\end{array}$




\section{Appendix A}

Table A1. List of cases consists of a seven-factor Box-Behnken design (low: -1 ; mid: 0; high: 1) and two extreme permutations (all low values and all high values).

\begin{tabular}{|c|c|c|c|c|c|c|c|}
\hline Case No. & Calcite & Kaolinite & Dolomite & Quartz & Ankerite & Siderite & Illite \\
\hline 1 & -1 & -1 & 0 & 0 & 0 & 0 & 0 \\
\hline 2 & 1 & -1 & 0 & 0 & 0 & 0 & 0 \\
\hline 3 & -1 & 1 & 0 & 0 & 0 & 0 & 0 \\
\hline 4 & 1 & 1 & 0 & 0 & 0 & 0 & 0 \\
\hline 5 & -1 & 0 & -1 & 0 & 0 & 0 & 0 \\
\hline 6 & 1 & 0 & -1 & 0 & 0 & 0 & 0 \\
\hline 7 & -1 & 0 & 1 & 0 & 0 & 0 & 0 \\
\hline 8 & 1 & 0 & 1 & 0 & 0 & 0 & 0 \\
\hline 9 & -1 & 0 & 0 & -1 & 0 & 0 & 0 \\
\hline 10 & 1 & 0 & 0 & -1 & 0 & 0 & 0 \\
\hline 11 & -1 & 0 & 0 & 1 & 0 & 0 & 0 \\
\hline 12 & 1 & 0 & 0 & 1 & 0 & 0 & 0 \\
\hline 13 & -1 & 0 & 0 & 0 & -1 & 0 & 0 \\
\hline 14 & 1 & 0 & 0 & 0 & -1 & 0 & 0 \\
\hline 15 & -1 & 0 & 0 & 0 & 1 & 0 & 0 \\
\hline 16 & 1 & 0 & 0 & 0 & 1 & 0 & 0 \\
\hline 17 & -1 & 0 & 0 & 0 & 0 & -1 & 0 \\
\hline 18 & 1 & 0 & 0 & 0 & 0 & -1 & 0 \\
\hline 19 & -1 & 0 & 0 & 0 & 0 & 1 & 0 \\
\hline 20 & 1 & 0 & 0 & 0 & 0 & 1 & 0 \\
\hline 21 & -1 & 0 & 0 & 0 & 0 & 0 & -1 \\
\hline 22 & 1 & 0 & 0 & 0 & 0 & 0 & -1 \\
\hline 23 & -1 & 0 & 0 & 0 & 0 & 0 & 1 \\
\hline 24 & 1 & 0 & 0 & 0 & 0 & 0 & 1 \\
\hline 25 & 0 & -1 & -1 & 0 & 0 & 0 & 0 \\
\hline 26 & 0 & 1 & -1 & 0 & 0 & 0 & 0 \\
\hline 27 & 0 & -1 & 1 & 0 & 0 & 0 & 0 \\
\hline 28 & 0 & 1 & 1 & 0 & 0 & 0 & 0 \\
\hline 29 & 0 & -1 & 0 & -1 & 0 & 0 & 0 \\
\hline 30 & 0 & 1 & 0 & -1 & 0 & 0 & 0 \\
\hline 31 & 0 & -1 & 0 & 1 & 0 & 0 & 0 \\
\hline 32 & 0 & 1 & 0 & 1 & 0 & 0 & 0 \\
\hline 33 & 0 & -1 & 0 & 0 & -1 & 0 & 0 \\
\hline 34 & 0 & 1 & 0 & 0 & -1 & 0 & 0 \\
\hline 35 & 0 & -1 & 0 & 0 & 1 & 0 & 0 \\
\hline 36 & 0 & 1 & 0 & 0 & 1 & 0 & 0 \\
\hline 37 & 0 & -1 & 0 & 0 & 0 & -1 & 0 \\
\hline 38 & 0 & 1 & 0 & 0 & 0 & -1 & 0 \\
\hline 39 & 0 & -1 & 0 & 0 & 0 & 1 & 0 \\
\hline 40 & 0 & 1 & 0 & 0 & 0 & 1 & 0 \\
\hline 41 & 0 & -1 & 0 & 0 & 0 & 0 & -1 \\
\hline 42 & 0 & 1 & 0 & 0 & 0 & 0 & -1 \\
\hline 43 & 0 & -1 & 0 & 0 & 0 & 0 & 1 \\
\hline
\end{tabular}


Table A1. Cont.

\begin{tabular}{|c|c|c|c|c|c|c|c|}
\hline 44 & 0 & 1 & 0 & 0 & 0 & 0 & 1 \\
\hline 45 & 0 & 0 & -1 & -1 & 0 & 0 & 0 \\
\hline 46 & 0 & 0 & 1 & -1 & 0 & 0 & 0 \\
\hline 47 & 0 & 0 & -1 & 1 & 0 & 0 & 0 \\
\hline 48 & 0 & 0 & 1 & 1 & 0 & 0 & 0 \\
\hline 49 & 0 & 0 & -1 & 0 & -1 & 0 & 0 \\
\hline 50 & 0 & 0 & 1 & 0 & -1 & 0 & 0 \\
\hline 51 & 0 & 0 & -1 & 0 & 1 & 0 & 0 \\
\hline 52 & 0 & 0 & 1 & 0 & 1 & 0 & 0 \\
\hline 53 & 0 & 0 & -1 & 0 & 0 & -1 & 0 \\
\hline 54 & 0 & 0 & 1 & 0 & 0 & -1 & 0 \\
\hline 55 & 0 & 0 & -1 & 0 & 0 & 1 & 0 \\
\hline 56 & 0 & 0 & 1 & 0 & 0 & 1 & 0 \\
\hline 57 & 0 & 0 & -1 & 0 & 0 & 0 & -1 \\
\hline 58 & 0 & 0 & 1 & 0 & 0 & 0 & -1 \\
\hline 59 & 0 & 0 & -1 & 0 & 0 & 0 & 1 \\
\hline 60 & 0 & 0 & 1 & 0 & 0 & 0 & 1 \\
\hline 61 & 0 & 0 & 0 & -1 & -1 & 0 & 0 \\
\hline 62 & 0 & 0 & 0 & 1 & -1 & 0 & 0 \\
\hline 63 & 0 & 0 & 0 & -1 & 1 & 0 & 0 \\
\hline 64 & 0 & 0 & 0 & 1 & 1 & 0 & 0 \\
\hline 65 & 0 & 0 & 0 & -1 & 0 & -1 & 0 \\
\hline 66 & 0 & 0 & 0 & 1 & 0 & -1 & 0 \\
\hline 67 & 0 & 0 & 0 & -1 & 0 & 1 & 0 \\
\hline 68 & 0 & 0 & 0 & 1 & 0 & 1 & 0 \\
\hline 69 & 0 & 0 & 0 & -1 & 0 & 0 & -1 \\
\hline 70 & 0 & 0 & 0 & 1 & 0 & 0 & -1 \\
\hline 71 & 0 & 0 & 0 & -1 & 0 & 0 & 1 \\
\hline 72 & 0 & 0 & 0 & 1 & 0 & 0 & 1 \\
\hline 73 & 0 & 0 & 0 & 0 & -1 & -1 & 0 \\
\hline 74 & 0 & 0 & 0 & 0 & 1 & -1 & 0 \\
\hline 75 & 0 & 0 & 0 & 0 & -1 & 1 & 0 \\
\hline 76 & 0 & 0 & 0 & 0 & 1 & 1 & 0 \\
\hline 77 & 0 & 0 & 0 & 0 & -1 & 0 & -1 \\
\hline 78 & 0 & 0 & 0 & 0 & 1 & 0 & -1 \\
\hline 79 & 0 & 0 & 0 & 0 & -1 & 0 & 1 \\
\hline 80 & 0 & 0 & 0 & 0 & 1 & 0 & 1 \\
\hline 81 & 0 & 0 & 0 & 0 & 0 & -1 & -1 \\
\hline 82 & 0 & 0 & 0 & 0 & 0 & 1 & -1 \\
\hline 83 & 0 & 0 & 0 & 0 & 0 & -1 & 1 \\
\hline 84 & 0 & 0 & 0 & 0 & 0 & 1 & 1 \\
\hline 85 & 0 & 0 & 0 & 0 & 0 & 0 & 0 \\
\hline 86 & -1 & -1 & -1 & -1 & -1 & -1 & -1 \\
\hline 87 & 1 & 1 & 1 & 1 & 1 & 1 & 1 \\
\hline
\end{tabular}



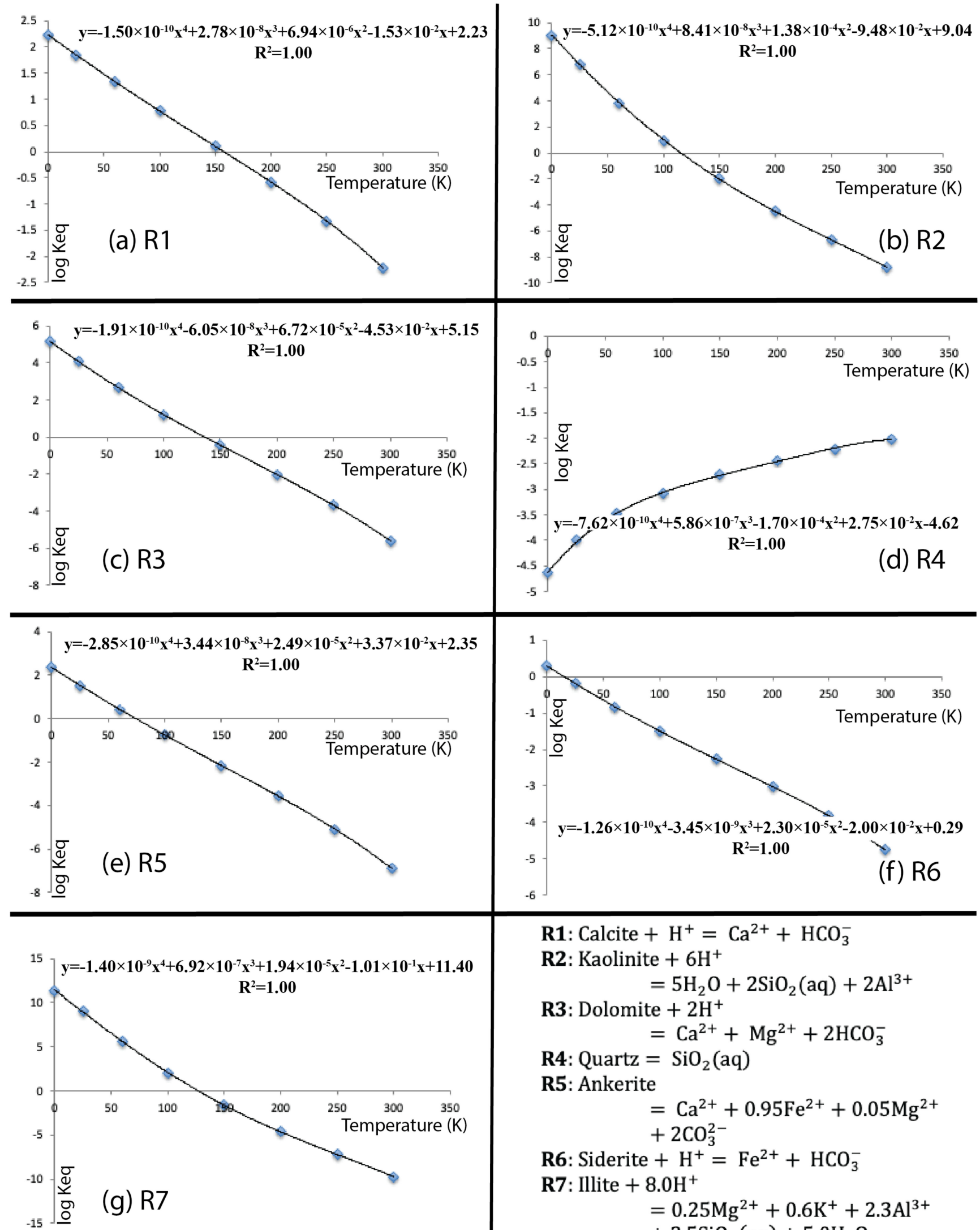

R1: Calcite $+\mathrm{H}^{+}=\mathrm{Ca}^{2+}+\mathrm{HCO}_{3}^{-}$

R2: Kaolinite $+6 \mathrm{H}^{+}$

$$
=5 \mathrm{H}_{2} \mathrm{O}+2 \mathrm{SiO}_{2}(\mathrm{aq})+2 \mathrm{Al}^{3+}
$$

R3: Dolomite $+2 \mathrm{H}^{+}$

$$
=\mathrm{Ca}^{2+}+\mathrm{Mg}^{2+}+2 \mathrm{HCO}_{3}^{-}
$$

R4: Quartz $=\mathrm{SiO}_{2}(\mathrm{aq})$

R5: Ankerite

$$
\begin{aligned}
& =\mathrm{Ca}^{2+}+0.95 \mathrm{Fe}^{2+}+0.05 \mathrm{Mg}^{2+} \\
& +2 \mathrm{CO}_{3}^{2-}
\end{aligned}
$$

R6: Siderite $+\mathrm{H}^{+}=\mathrm{Fe}^{2+}+\mathrm{HCO}_{3}^{-}$

R7: Illite $+8.0 \mathrm{H}^{+}$

$$
\begin{aligned}
& =0.25 \mathrm{Mg}^{2+}+0.6 \mathrm{~K}^{+}+2.3 \mathrm{Al}^{3+} \\
& +3.5 \mathrm{SiO}_{2}(\mathrm{aq})+5.0 \mathrm{H}_{2} \mathrm{O}
\end{aligned}
$$

Figure A1. Relationship between chemical equilibrium constants and temperature based on the EQ3/6 database (blue diamonds) for determining the chemical equilibrium constants of seven mineral reactions [43]. 
(a) $\mathrm{pH}$

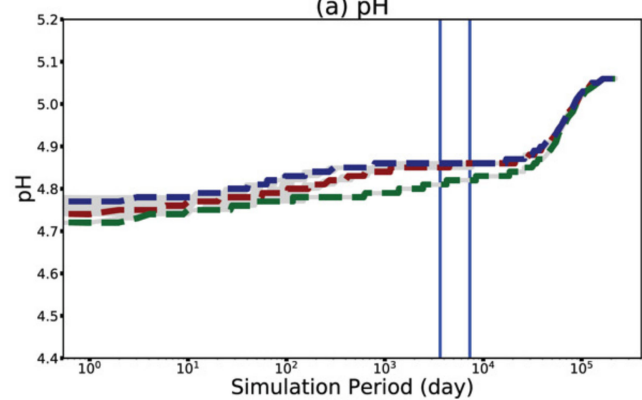

(c) Kaolinite

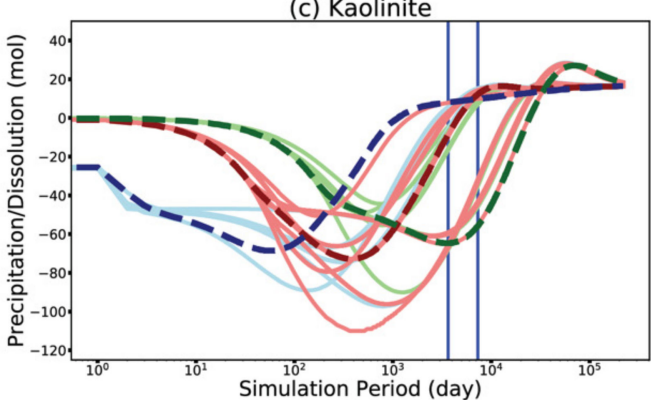

(b) Illite

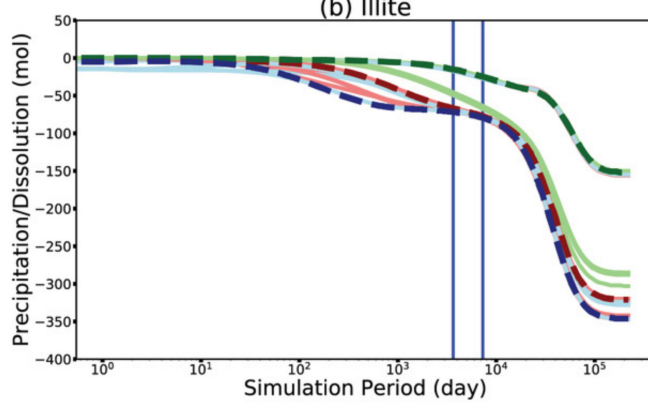

(d) Quartz

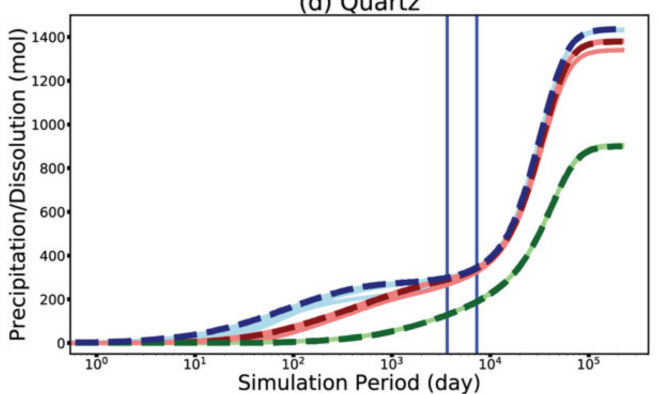

Figure A2. Predicted values from the 2-phase models: (a) $\mathrm{pH}$, mineral precipitation or dissolution of (b) illite, (c) kaolinite, and (d) quartz at the center of the model. Light green, light red, and light blue indicate low, mid, and high RSA of the particular mineral in each subplot; dashed lines in dark green, dark red, and dark blue indicate Case\#86, Case \#85, and Case \#87, respectively; two vertical lines denote the end of 10 years and the end of 20 years.
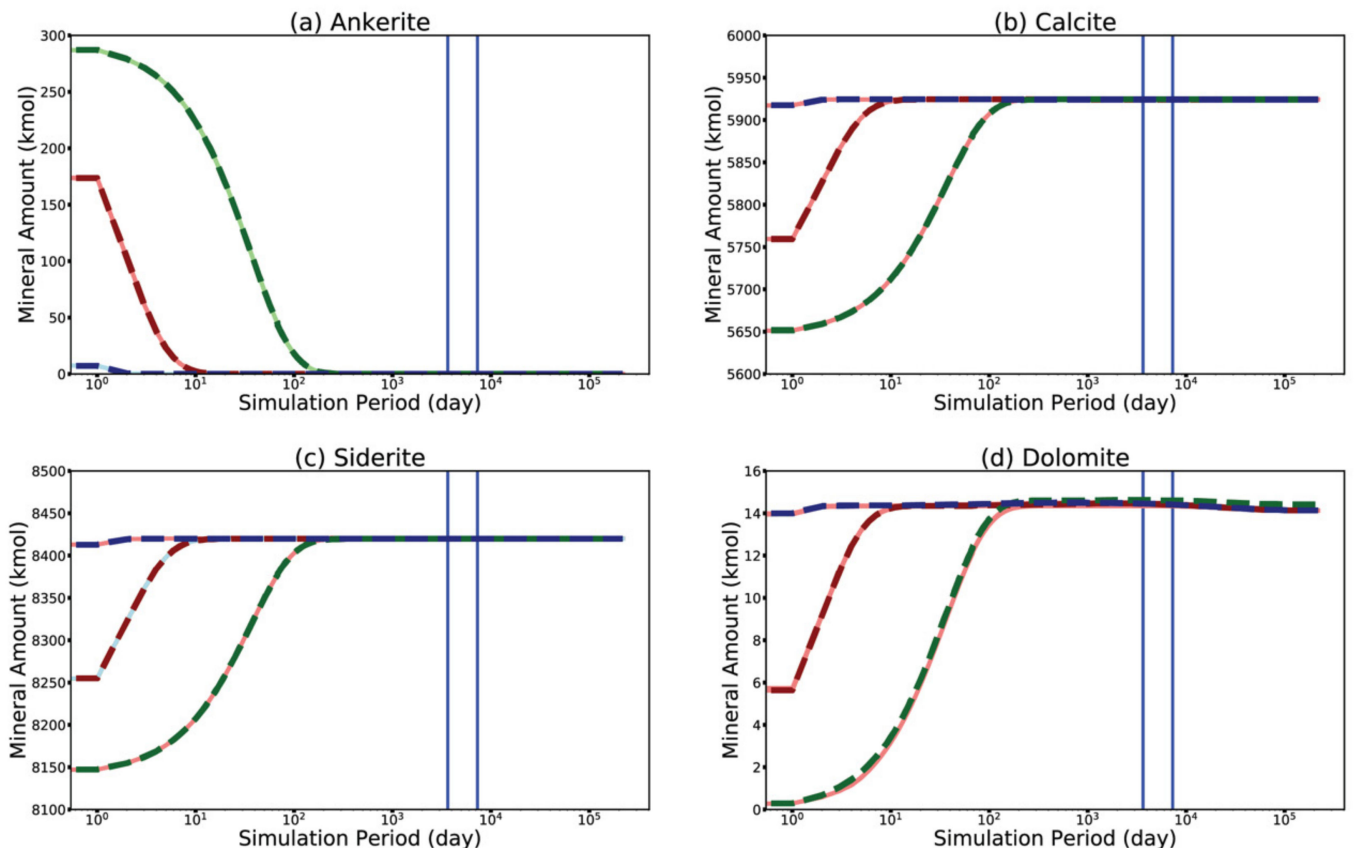

Figure A3. Predicted total mineral amount in the simplified model with only water and $\mathrm{CO}_{2}$ : (a) ankerite, (b) calcite, (c) siderite, and (d) dolomite. Light green, light red, and light blue indicate low, mid, and high RSA of the particular mineral in each subplot; dashed lines in dark green, dark red, and dark blue indicate Case\#86, Case \#85, and Case \#87, respectively; two vertical lines denote the end of 10 years and the end of 20 years. 


\section{Appendix B}

The flow equations of the CMG-GEM simulation package include:

$$
\begin{gathered}
\psi_{i} \equiv \Delta T_{o}^{m} y_{i o}^{m}\left(\Delta p^{n+1}-\gamma_{o}^{m} \Delta D\right)+\Delta T_{g}^{m} y_{i g}^{m}\left(\Delta p^{n+1}+\Delta P \operatorname{cog} m-\gamma_{g}^{m} \Delta D\right)+q_{i}^{m}-\frac{V}{\Delta t}\left[N_{i}^{n+1}-N_{i}^{n}\right]=0 \\
i=1, \cdots, n_{c} \\
\psi_{n_{c}+1} \equiv T_{w}^{m}\left(\Delta p^{n+1}+\Delta P_{c w o}^{m}-\gamma_{g}^{m} \Delta D\right)+q_{n_{c}+1}^{m}-\frac{V}{\Delta t}\left[N_{n_{c}+1}^{n+1}-N_{n_{c}+1}^{n}\right]=0 \\
N_{i}=\phi\left(\rho_{o} S_{o} y_{i o}+\rho_{g} S_{g} y_{i g}\right) \\
N_{n_{c}+1}=\phi \rho_{w} S_{w}
\end{gathered}
$$

\section{References}

1. Lackner, K.S. A guide to $\mathrm{CO}_{2}$ sequestration. Science 2003, 300, 1677-1678. [CrossRef] [PubMed]

2. Metz, B.; Davidson, O.; De Coninck, H.C.; Loos, M.; Meyer, L.A. IPCC special report on carbon dioxide capture and storage. In Working Group III of the Intergovernmental Panel on Climate Change; IPCC: Geneva, Switzerland; Cambridge University Press: Cambridge, UK, 2005; Volume 4.

3. Pacala, S.; Socolow, R. Stabilization wedges: solving the climate problem for the next 50 years with current technologies. Science 2004, 305, 968-972. [CrossRef]

4. Jia, W.; McPherson, B. Chapter 6-Multiphase Flow Associated with Geological $\mathrm{CO}_{2}$ Storage. In Science of Carbon Storage in Deep Saline Formations; Newell, P., Ilgen, A.G., Eds.; Elsevier: Amsterdam, The Netherlands, 2019; pp. 117-143. ISBN 978-0-12-812752-0.

5. Han, W.S.; McPherson, B.J.; Lichtner, P.C.; Wang, F.P. Evaluation of trapping mechanisms in geologic $\mathrm{CO}_{2}$ sequestration: Case study of SACROC northern platform, a 35-year $\mathrm{CO}_{2}$ injection site. Am. J. Sci. 2010, 310, 282-324. [CrossRef]

6. Jia, W.; McPherson, B.J.; Pan, F.; Xiao, T.; Bromhal, G. Probabilistic analysis of $\mathrm{CO}_{2}$ storage mechanisms in a $\mathrm{CO}_{2}-\mathrm{EOR}$ field using polynomial chaos expansion. Int. J. Greenh. Gas Control 2016, 51, 218-229. [CrossRef]

7. Kutsienyo, E.J.; Ampomah, W.; Sun, Q.; Balch, R.S.; You, J.; Aggrey, W.N.; Cather, M. Evaluation of CO-EOR Performance and Storage Mechanisms in an Active Partially Depleted Oil Reservoir; Society of Petroleum Engineers (SPE): London, UK, 2019.

8. Sun, Q.; Ampomah, W.; Kutsienyo, E.J.; Appold, M.; Adu-Gyamfi, B.; Dai, Z.; Soltanian, M.R. Assessment of $\mathrm{CO}_{2}$ trapping mechanisms in partially depleted oil-bearing sands. Fuel 2020, 278, 118356. [CrossRef]

9. Bethke, C.M. Geochemical Reaction Modeling: Concepts and Applications; Oxford University Press: Oxford, UK, 1996; ISBN 0195094751.

10. Brunauer, S.; Emmett, P.H.; Teller, E. Adsorption of Gases in Multimolecular Layers. J. Am. Chem. Soc. 1938, 60, 309-319. [CrossRef]

11. Beckingham, L.E.; Mitnick, E.H.; Steefel, C.I.; Zhang, S.; Voltolini, M.; Swift, A.M.; Yang, L.; Cole, D.R.; Sheets, J.M.; Ajo-Franklin, J.B.; et al. Evaluation of mineral reactive surface area estimates for prediction of reactivity of a multi-mineral sediment. Geochim. Cosmochim. Acta 2016, 188, 310-329. [CrossRef]

12. Beckingham, L.E. Evaluation of Macroscopic Porosity-Permeability Relationships in Heterogeneous Mineral Dissolution and Precipitation Scenarios. Water Resour. Res. 2017, 53, 10217-10230. [CrossRef]

13. Bourg, I.C.; Beckingham, L.E.; DePaolo, D.J. The Nanoscale Basis of $\mathrm{CO}_{2}$ Trapping for Geologic Storage. Environ. Sci. Technol. 2015, 49, 10265-10284. [CrossRef]

14. Jia, W.; McPherson, B.; Pan, F.; Dai, Z.; Xiao, T. Uncertainty quantification of $\mathrm{CO}_{2}$ storage using Bayesian model averaging and polynomial chaos expansion. Int. J. Greenh. Gas Control 2018, 71. [CrossRef]

15. Dai, Z.; Viswanathan, H.; Xiao, T.; Middleton, R.; Pan, F.; Ampomah, W.; Yang, C.; Zhou, Y.; Jia, W.; Lee, S.-Y.; et al. $\mathrm{CO}_{2}$ Sequestration and Enhanced Oil Recovery at Depleted Oil/Gas Reservoirs. Energy Procedia 2017, 114, 6957-6967. [CrossRef]

16. Xiao, T.; McPherson, B.; Pan, F.; Esser, R.; Jia, W.; Bordelon, A.; Bacon, D. Potential chemical impacts of $\mathrm{CO}_{2}$ leakage on underground source of drinking water assessed by quantitative risk analysis. Int. J. Greenh. Gas Control 2016, 50. [CrossRef]

17. Xiao, T.; McPherson, B.; Esser, R.; Jia, W.; Dai, Z.; Chu, S.; Pan, F.; Viswanathan, H. Chemical Impacts of Potential $\mathrm{CO}_{2}$ and Brine Leakage on Groundwater Quality with Quantitative Risk Assessment: A Case Study of the Farnsworth Unit. Energies 2020, 13, 6574. [CrossRef]

18. You, J.; Ampomah, W.; Sun, Q. Co-optimizing water-alternating-carbon dioxide injection projects using a machine learning assisted computational framework. Appl. Energy 2020, 279, 115695. [CrossRef]

19. Jia, W.; Mcpherson, B.; Pan, F.; Dai, Z.; Moodie, N.; Xiao, T. Impact of Three-Phase Relative Permeability and Hysteresis Models on Forecasts of Storage Associated with $\mathrm{CO}_{2}$-EOR. Water Resour. Res. 2018, 54, 1109-1126. [CrossRef]

20. Dai, Z.; Xu, L.; Xiao, T.; McPherson, B.; Zhang, X.; Zheng, L.; Dong, S.; Yang, Z.; Soltanian, M.R.; Yang, C.; et al. Reactive chemical transport simulations of geologic carbon sequestration: Methods and applications. Earth-Sci. Rev. 2020, 208, 103265. [CrossRef]

21. Qin, F.; Beckingham, L.E. The impact of mineral reactive surface area variation on simulated mineral reactions and reaction rates. Appl. Geochem. 2021, 124, 104852. [CrossRef] 
22. Luo, S.; Xu, R.; Jiang, P. Effect of reactive surface area of minerals on mineralization trapping of $\mathrm{CO}_{2}$ in saline aquifers. Pet. Sci. 2012, 9, 400-407. [CrossRef]

23. Bolourinejad, P.; Shoeibi Omrani, P.; Herber, R. Effect of reactive surface area of minerals on mineralization and carbon dioxide trapping in a depleted gas reservoir. Int. J. Greenh. Gas Control 2014, 21, 11-22. [CrossRef]

24. Jia, W.; Xiao, T.; Moodie, N.; McPherson, B. Uncertainty Analysis of Impact of Geochemical Reactions on Forecasting $\mathrm{CO}_{2}$ Storage at a Depleted Oil Field. In Proceedings of the 2019 AIChE Annual Meeting, Orlando, FL, USA, 13 November 2019.

25. Wu, Z.; Luhmann, A.J.; Rinehart, A.J.; Mozley, P.S.; Dewers, T.A.; Heath, J.E.; Majumdar, B.S. Chemo-mechanical Alterations Induced from $\mathrm{CO}_{2}$ Injection in Carbonate-Cemented Sandstone: An Experimental Study at $71^{\circ} \mathrm{C}$ and $29 \mathrm{MPa}$. J. Geophys. Res. Solid Earth 2020, 125, e2019JB019096. [CrossRef]

26. Ampomah, W.; Balch, R.S.; Ross-Coss, D.; Hutton, A.; Cather, M.; Will, R.A. An Integrated Approach for Characterizing a Sandstone Reservoir in the Anadarko Basin. In Proceedings of the Offshore Technology Conference, Houston, TX, USA, 2-5 May 2016.

27. Ross-Coss, D.; Ampomah, W.; Cather, M.; Balch, R.S.; Mozley, P.; Rasmussen, L. An improved approach for sandstone reservoir characterization. In Proceedings of the SPE Western Regional Meeting, Anchorage, AK, USA, 23-26 May 2016.

28. Kumar, A.; Chao, K.; Hammack, R.; Harbert, W.; Ampomah, W.; Balch, R.; Garcia, L. Surface-seismic monitoring of an active $\mathrm{CO}_{2}$-EOR operation in the Texas Panhandle using broadband seismometers. In SEG Technical Program Expanded Abstracts 2018; Society of Exploration Geophysicists: Huston, TX, USA, 2018; pp. 3027-3031. ISBN 1949-4645.

29. Dai, Z.; Middleton, R.; Viswanathan, H.; Fessenden-Rahn, J.; Bauman, J.; Pawar, R.; Lee, S.-Y.; McPherson, B. An integrated framework for optimizing $\mathrm{CO}_{2}$ sequestration and enhanced oil recovery. Environ. Sci. Technol. Lett. 2013, 1, 49-54. [CrossRef]

30. Xiao, T.; McPherson, B.; Bordelon, A.; Viswanathan, H.; Dai, Z.; Tian, H.; Esser, R.; Jia, W.; Carey, W. Quantification of CO ${ }_{2}-$ cement-rock interactions at the well-caprock-reservoir interface and implications for geological $\mathrm{CO}_{2}$ storage. Int. J. Greenh. Gas Control 2017, 63, 126-140. [CrossRef]

31. Xiao, T.; Xu, H.; Moodie, N.; Esser, R.; Jia, W.; Zheng, L.; Rutqvist, J.; McPherson, B. Chemical-Mechanical Impacts of CO 2 Intrusion into Heterogeneous Caprock. Water Resour. Res. 2020, 56, e2020WR027193. [CrossRef]

32. Rose-Coss, D.; Wampomah, W.; Hutton, A.C.; Gragg, E.; Mozley, P.; Balch, R.S.; Grigg, R. Geologic Characterization for CO 2 -EOR Simulation: A Case Study of the Farnsworth Unit, Anadarko Basin, Texas. In Proceedings of the AAPG Annual Convention and Exhibition, Socorro, NM, USA, 2 June 2015.

33. Balch, R.; Grigg, R.; McPherson, B. Overview of a Large Scale Carbon Capture, Utilization, and Storage Demonstration Project in an Active Oil Field in Texas, USA. Energy Procedia 2017, 114, 5874-5887. [CrossRef]

34. Ampomah, W.; Balch, R.; Cather, M.; Rose-Coss, D.; Dai, Z.; Heath, J.E.; Dewers, T.; Mozley, P. Evaluation of CO 2 Storage Mechanisms in $\mathrm{CO}_{2}$ Enhanced Oil Recovery Sites: Application to Morrow Sandstone Reservoir. Energy Fuels 2016, 30, 8545-8555. [CrossRef]

35. Moodie, N.; Pan, F.; Jia, W.; McPherson, B. Impacts of relative permeability formulation on forecasts of $\mathrm{CO}_{2}$ phase behavior, phase distribution, and trapping mechanisms in a geologic carbon storage reservoir. Greenh. Gases Sci. Technol. 2017, 7, 958-962. [CrossRef]

36. Moodie, N.; Ampomah, W.; Jia, W.; Heath, J.; McPherson, B. Assignment and calibration of relative permeability by hydrostratigraphic units for multiphase flow analysis, case study: $\mathrm{CO}_{2}-\mathrm{EOR}$ operations at the Farnsworth Unit, Texas. Int. J. Greenh. Gas Control 2019, 81. [CrossRef]

37. Dai, Z.; Viswanathan, H.; Middleton, R.; Pan, F.; Ampomah, W.; Yang, C.; Jia, W.; Xiao, T.; Lee, S.-Y.; McPherson, B. CO 2 Accounting and Risk Analysis for $\mathrm{CO}_{2}$ Sequestration at Enhanced Oil Recovery Sites. Environ. Sci. Technol. 2016, 50, 7546-7554. [CrossRef]

38. Pan, F.; McPherson, B.J.; Dai, Z.; Jia, W.; Lee, S.-Y.; Ampomah, W.; Viswanathan, H.; Esser, R. Uncertainty analysis of carbon sequestration in an active $\mathrm{CO}_{2}$-EOR field. Int. J. Greenh. Gas Control 2016, 51. [CrossRef]

39. Jia, W.; Pan, F.; Dai, Z.; Xiao, T.; McPherson, B. Probabilistic Risk Assessment of $\mathrm{CO}_{2}$ Trapping Mechanisms in a Sandstone $\mathrm{CO}_{2}$-EOR Field in Northern Texas, USA. Energy Procedia 2017, 114, 4321-4329. [CrossRef]

40. Landrot, G.; Ajo-Franklin, J.B.; Yang, L.; Cabrini, S.; Steefel, C.I. Measurement of accessible reactive surface area in a sandstone, with application to $\mathrm{CO}_{2}$ mineralization. Chem. Geol. 2012, 318-319, 113-125. [CrossRef]

41. Waldmann, S. Geological and Mineralogical Investigation of Rotliegend Gas Reservoirs in the Netherlands and Their Potential for $\mathrm{CO}_{2}$ Storage. Ph.D. Thesis, Friedrich-Schiller-Universität Jena, Jena, Germany, 2011.

42. Ampomah, W.; Balch, R.S.; Grigg, R.B.; McPherson, B.; Will, R.A.; Lee, S.; Dai, Z.; Pan, F. Co-optimization of CO 2 -EOR and storage processes in mature oil reservoirs. Greenh. Gases Sci. Technol. 2016, 7, 128-142. [CrossRef]

43. Wolery, T.J. EQ3/6, a Software Package for Geochemical Modeling of Aqueous Systems: Package Overview and Installation Guide (Version 7.0); Lawrence Livermore National Lab.: Livermore, CA, USA, 1992.

44. Palandri, J.L.; Kharaka, Y.K. A Compilation of Rate Parameters of Water-Mineral Interaction Kinetics for Application to Geochemical Modeling; Geological Survey: Menlo Park, CA, USA, 2004.

45. Pan, F.; McPherson, B.J.; Esser, R.; Xiao, T.; Appold, M.S.; Jia, W.; Moodie, N. Forecasting evolution of formation water chemistry and long-term mineral alteration for GCS in a typical clastic reservoir of the Southwestern United States. Int. J. Greenh. Gas Control 2016, 54. [CrossRef] 
46. Tao, J.; Wu, Y.; Elsworth, D.; Li, P.; Hao, Y. Coupled Thermo-Hydro-Mechanical-Chemical Modeling of Permeability Evolution in a $\mathrm{CO}_{2}$-Circulated Geothermal Reservoir. Geofluids 2019, 2019, 5210730. [CrossRef]

47. Fan, C.; Elsworth, D.; Li, S.; Zhou, L.; Yang, Z.; Song, Y. Thermo-hydro-mechanical-chemical couplings controlling $\mathrm{CH}_{4}$ production and $\mathrm{CO}_{2}$ sequestration in enhanced coalbed methane recovery. Energy 2019, 173, 1054-1077. [CrossRef]

48. Tahmasebi, P.; Kamrava, S. A pore-scale mathematical modeling of fluid-particle interactions: Thermo-hydro-mechanical coupling. Int. J. Greenh. Gas Control 2019, 83, 245-255. [CrossRef] 